\title{
Potential Application of Glomus Intraradices (AMF) and Different Isolates of PGPR (Biotol) to Enhance the Yield and Quality of Wheat Grown in The Field in Calcareous Soil Under Different Salinity Levels
}

\author{
Aboul-Nasr, A. ${ }^{1}$, Al-Fayoumy, M.E. ${ }^{2}$, Aboul-Magd, M. ${ }^{3}$ and A. Elhabbab ${ }^{1}$ \\ 1- Dept.of Agricultural Botany, Agricultural Microbiology, Fac. of Agric., Saba- \\ Basha, Alexandria University, Egypt. \\ 2- Soil, Water and Environment Res. Inst., Agric. Res. Center, Nubaria Research Station. \\ 3- Dept. of Soil and Agric, Chemistry, Plant Nutrition and Soil Fertility, Fac. of Agric., \\ Saba-Basha, Alexandria University, Egypt.
}

\begin{abstract}
Two field experiments were carried out at the farm of Nubaria Agricultural Research Station during the two winter seasons of 2012/2013 and 2013/2014, to study the effect of the arbuscular mycorrhizal fungus, Glomus intraradices and the plant growth promoting rhizobacteria (Biotol) on growth, yield parameters and chemical contents of two wheat cultivars (Sakha 93 and Gemmeza 9) grown in calcareous soil under four levels of soil salinity and four rates of NPK mineral fertilizers. Results indicated that, wheat plants inoculated with AMF and Biotol together significantly decreased $\mathrm{Na}$ shoot content $(\mathrm{mg} / \mathrm{kg})$, increased NPK uptake, proline and salicylic acid contents, chlorophyll and grain protein at all the tested salinity levels compared to uninoculated plants. Under normal salinity level $\left(\leq 4 \mathrm{dSm}^{-1}\right)$, dual inoculation with AMF and Biotol resulted total grain yield to 6.5 and 6.7 t/ha for Sakha 93 and Gemmeza 9, respectively, in the presence of NPK $100 \%$ with a percentage increases of 41 and 29 more than un-inoculated plants. Results clearly indicated that, proline and Salicylic acid content were significantly increased in dual inoculated plants in Sakha 93 comparing to Gemmeza 9 under soil salinity up to $8 \mathrm{dSm}^{-1}$. The percentage increases were 38.6 and 37.54 for proline and 192.57 and 135.42 for salicylic acid in case of Sakha 93 and Gemmeza 9, respectively, in the presence of NPK75\% and soil salinity 8-12 $\mathrm{dSm}^{-1}$. No significant differences were observed among plants inoculated with $G$. intraradices and PGPR either in the presence of 75 or $100 \%$ of the recommended dose of NPK. Summing up it could be concluded that inoculation with AMF and Biotol successfully improve the growth, yield and salt stress tolerance of the tested cultivars in calcareous soil.
\end{abstract}

Key words: arbuscular mycorrhizal fungus, PGPR, salinity, wheat, proline, salicylic acid

\section{INTRODUCTION}

Wheat (Triticum aestivum L.) is the most important cereal crop in Egypt. Increasing wheat production is an essential national target to fill the gap between production and consumption (Tawfik et al. 2006). Salinity is one of the most brutal environmental factors limiting the productivity of crop plants because most of them are sensitive to salinity caused by high concentrations of salts in the soil (Shrivastava and Kumar, 2015). Salinity affects almost all aspects of plant development including: germination, vegetative growth and reproductive development. Soil salinity imposes ion toxicity, osmotic stress, nutrient $(\mathrm{N}, \mathrm{Ca}, \mathrm{K}$, $\mathrm{P}, \mathrm{Fe}$, and $\mathrm{Zn}$ ) deficiency and oxidative stress on plants, and thus limits water uptake from soil, some elements, such as sodium, chlorine, and boron besides having specific toxic effects on plants. Excessive accumulation of sodium in cell walls can rapidly lead to osmotic stress and cell death (Munns et al. 2002). Salinity and drought stresses inhibit the production of auxins, gibberellins, and zeatin in 
the roots and leaves of plants (Sakhabutdinova et al. 2003; Figueiredo et al. 2008; Perez-Alfocea et al., 2010).Calcareous soils occupy wide areas in the North African countries such as Egypt. These soils have a high percentage of calcium carbonate and normally basic in their reaction. Low soil fertility and nutrients deficiency in calcareous soils are very common and could be considered the main constraints for agricultural production in some cases (Hilal et al. 1990; Awad et al. 1996).Several strategies have been developed in order to decrease the toxic effects caused by high salinity on plant growth, such as mycorrhizal fungi (Cho et al. 2006 and Kohler et al. 2009) and plant growth-promoting bacteria (PGPB) (Kohler et al. 2006 and Dimkpa et al. 2009).

Under salt stress conditions, plant tolerance and production are complicated mechanisms. Arbuscular mycorrhizal fungi employ different mechanisms to enhance salt tolerance of host plants such as enhancing nutrient acquisition (P, N, Mg and Ca) (Azcon and El-Atrash 1997; Giri and Mukerji 2004 and Sheng et al., 2009), inhibiting high uptake of $\mathrm{Na}$ and $\mathrm{Cl}$ and their transport to plant shoots (Dai et al. 2009), improving water uptake (Ruiz-Lozano and Azcon 2000), accumulating of proline and polyamines (Evelin et al. 2009) and increasing some of enzymatic antioxidant defense system (SOD and CAT) (Wu et al. 2010). Other arbuscular mycorrhizal mechanisms may include an osmotic adjustment, which assist in maintaining the leaf turgor pressure, and effects on the photosynthesis, transpiration, stomatal conductance and water use efficiency (Juniper and Abbott, 1993).

Tank and Saraf (2010) showed that PGPRs which are able to solubilize phosphate, produce phytohormones and siderophores in salt condition promote growth of tomato plants under $2 \% \mathrm{NaCl}$ stress. PGPR are able to increase AM fungal development by affecting root colonization as well as by enhancing plant $\mathrm{N}$ and $P$ uptake (Artursson et al. 2006 and Richardson et al. 2009). There are different examples of enhanced associations between different bacterial strains including Bacillus, Paenibacillus, Pseudomonas and Rhizobia and different AM species including G. clarum, G. intraradices, G. mosseae, and G. versiforme (Artursson et al. 2006). These stimulating effects include the growth of fungi and germination of then spores, respectively, root colonization of the host plant by AM fungi, the solubilization of phosphate, and the suppression of pathogens (Artursson et al. 2006).

The external hyphae of mycorrhizal fungi, which were about 100 times finer than wheat roots and 10 times finer than root hairs, access sites normally not permeable by roots or root hairs, thus reducing the $\mathrm{P}$ diffusion distances and increasing the surface area for nutrient absorption. Also, the length of external hyphae of mycorrhizal fungi can be a good predictor of its relative ability to take up $P$ (Manske et al. 2000).Proline levels were found to be increased significantly with salinity stress in mycorrhizal plants when compared to non-mycorrhizal plants. Marked increase in proline occurs in many plants during moderate or severe salt stress and this accumulation, mainly as a result of increased proline biosynthesis, is usually the most outstanding change among free amino acids (Hurkman et al. 1989). Salicylic acid (SA), a plant phenolic compound is considered as a hormone 
like endogenous regulator, and its role in the defence mechanisms against biotic and abiotic stresses has been well characterized (Szalai et al. 2009). The aim of this investigation is to study the effect of inoculation with Glomus intraradices and/or with different isolates of plant growth promoting rhizobacteria (Biotol) on growth, yield and chemical contents of two wheat cultivars grown under four levels of soil salinity in calcareous soil.

\section{MATERIALS AND METHODS}

\section{Soil physicochemical characteristic}

of the surface layers $(0-30 \mathrm{~cm})$ of the experimental field were as follows $\mathrm{pH}$ : 8.28-8.39, $\mathrm{CaCO}_{3} \%$ : 23.29-24.34, O.M. \%: 0.30-.045, available N: 50.48-40.36 $\mathrm{mg} / \mathrm{kg}$, available P: $3.59-3.00 \mathrm{mg} / \mathrm{kg}$ and available $\mathrm{K}: 107.13-85.96 \mathrm{mg} / \mathrm{kg}$. Soil texture was sandy loam (Page et al. 1982 and Klute, 1986).

\section{Wheat seeds:}

Two wheat (Triticum aestivum, L.) cultivars, Sakha 93 and Gemmeza 9, were provided from the Agricultural Research Center, Ministry of Agriculture, Giza, Egypt.

\section{Isolation of microorganisms and inoculums preparation}

1. The mycorrhizal strain Glomus intraradices, isolated from the Experimental Station of Alexandria University at Abies, (Aboul- Nasr, 1993), was used in both experiments. The inoculum consists of expanded clay aggregates $(2-4 \mathrm{~mm}$ in diameter, leca), containing chlamydospores and fungus mycelium, which had been produced on Tagetes erecta L. (Aboul-Nasr, 2004). Inoculant was thrown at the rate of $100 \mathrm{~g}$ per plot under wheat grains. The control plants received the same amount of heat sterilized expanded clay.

2. Biotol was used as plant growth promoting rhizobacteria (PGPR). Biotol contains a mixture of Bacillus megaterium, $B$. thuringiensis, $B$. mycoides, Paenibacillus graminis and $P$. borealis. It was obtained from the Soil, Water and Environment Research Institute - Agricultural Research Center, Giza, Egypt. It has added to the ground with the first irrigation after 25 days from sowing.

\section{NPK fertilizers:}

Four different rates of NPK fertilizers were used in this study (NPK $\mathrm{NPK}_{50 \%}, \mathrm{NPK}_{75 \%}$ and $\mathrm{NPK}_{100 \%}$ of the recommended dose). The recommended doses of $\mathrm{N}, \mathrm{P}_{2} \mathrm{O}_{5}$ and $\mathrm{K}_{2} \mathrm{O}$ fertilizers are 240,108 and $57.6 \mathrm{~kg} / \mathrm{ha}$, respectively. Nitrogen fertilizer (Ammonium nitrate $33.5 \% \mathrm{~N}$ ) was added twice in equal doses, at 25 and 45 days after sowing. Mono-calcium phosphate $\left(15.5 \% \mathrm{P}_{2} \mathrm{O}_{5}\right)$ was added at the time of soil preparation at one dose. Potassium sulphate $\left(48 \% \mathrm{~K}_{2} \mathrm{O}\right)$ was added at 45 days after sowing.

\section{Soil salinity levels:}

Four places with different salinity levels $\left(\mathrm{EC} \mathrm{dSm}{ }^{-1}\right.$ : average 2.8, 5.3, 7.6 and 10.5) were used in these experiments during the two growing seasons. 


\section{Field experiment:}

Two field experiments were carried out during two winter seasons of 2012/2013 and 2013/2014 at the Agricultural Research Station of Nubaria. The field experiments were laid out in a split-split -plot design with three replicates.

\section{The following parameters were measured:}

The percentage of mycorrhizal root length colonization

was estimated when plants were 45, 90 and 120 days old, according to Koske and Gemma (1989). The percentage of AM root colonization was estimated according to Giovannetti and Mosse (1980).

\section{0 grains weight $(g)$.}

1000 -grain weight was expressed as the weight of 1000 clean grains in grams.

\section{Grain yield t/ha.}

Grain yield was obtained by harvesting one square meter from each subsub plot. Plots were bundled, threshed, and then the grain were cleaned and weighted.

\section{Chemical analysis}

Plant samples were taken from each plot, at the suitable age, washed with running tap water, then distilled water. Samples were dried at $65^{\circ} \mathrm{C}$ till the weight constant. After dryness, the plant samples were milled well and stored for analysis. $0.5 \mathrm{~g}$ of plant powder was wet-digested with $\mathrm{H}_{2} \mathrm{SO}_{4}-\mathrm{H}_{2} \mathrm{O}_{2}$ digest (Lowther, 1980) and the following determinations were carried out in the digested solution.

\section{Shoot Na content}

It was carried out according to the method described by (Jackson, 1973) using Beckman flame photometer.

\section{Nitrogen uptake $(\mathrm{kg} / \mathrm{ha})$ and $\mathrm{N} \%$ in grains}

Total nitrogen was determined in digested wheat leaves colormeterically by Nessler's method (Chapman and Pratt, 1978) using $1 \mathrm{ml}$ of nessler solution $(35 \mathrm{~g}$ $\mathrm{Kl} / 100 \mathrm{ml}$ d.w $+20 \mathrm{~g} \mathrm{HgCl} / 500 \mathrm{ml} \mathrm{d.w})+120 \mathrm{~g} \mathrm{NaOH} / 250 \mathrm{ml} \mathrm{d} . \mathrm{w}$. Reading was achieved using wave length at $420 \mathrm{~nm}$ by spectrophotometer (Model 390, Agricultural Microbiology Lab at the Faculty of Agricultural Saba-Basha). The percentage of total nitrogen was calculated as follows:

$\% \mathrm{~N}=\mathrm{NH}_{4} \% \times 0.7764857$

Nitrogen uptake was calculated by multiplication of the $\mathrm{N}$ content $\times$ plant dry wt. (g).

The same method was use in case of determination $\mathrm{N} \%$ in grains.

\section{Phosphorus uptake (kg/ha)}

It was determined in shoots during both seasons by a mixture of sulphuric, nitric and perchloric acids (1: 10: $40 \mathrm{v}: \mathrm{v}: \mathrm{v}$ ) to determine the total phosphorus in wet ash. Phosphorus was determined by the Vanadomolybdate yellow method 
(Jackson, 1958) using Millton Ray spectronic 21 D. Phosphorus uptake was calculated by multiplication the P content $\times$ plant dry wt. $(\mathrm{g})$.

\section{Potassium uptake (kg/ha)}

Total potassium content in plant shoots and grains was determined using a mixture of sulphuric, nitric and perchloric acids (1: 10: $40 \mathrm{v}: \mathrm{v}$ : v) according to the method described by (Jackson, 1973) using Beckman flame photometer. Potassium uptake was calculated by multiplication the $\mathrm{K}$ content $\times$ plant dry wt. (g).

\section{Determination of chlorophyll index (SPAD)}

Chlorophyll index was measured by chlorophyll meter device (SPAD 502) Ganji Arjenaki et al. (2012).

\section{Determination of protein content in grains (\%)}

Protein was determined as percentage as follows: protein $\%=\mathrm{N} \% \times 6.24$

\section{Determination of proline ( $\mathrm{mg} / \mathrm{g}$ dry wt.)}

The content of proline was determined according to Umbreit et al. (1972) using the same extract prepared previously for the determination of total proteins and total soluble carbohydrates. $0.5 \mathrm{ml}$ of extract, $1 \mathrm{ml}$ citrate buffer (pH 5), $0.5 \mathrm{ml}$ ninhydrine and $3.5 \mathrm{ml}$ isopropanol solution were added. The optical density was measured spectrophotometerically at $450 \mathrm{~nm}$ for proline, $492 \mathrm{~nm}$ for phenylalanine and $515 \mathrm{~nm}$ for arginine. In addition, $0.5 \mathrm{ml}$ of distilled water was used instead of extract in reference cuvette. The concentration of each amino acid was determined according to the prepared standard curves of each corresponding amino acids.

\section{Determination of salicylic acids ( $\mathrm{mg} / 100 \mathrm{~g}$ root dry wt.)}

Determination was implemented according to the method of lqbal and Vaid (2009) and Malamy et al. (1992) as follows;

1. One gram of frozen root tissue is ground in $3.0 \mathrm{ml}$ methanol $90 \%$ and centrifuged at 6000 r.p.m. for $15 \mathrm{~min}$.

2. The pellet is re-extracted with $3.0 \mathrm{ml} 90 \%$ methanol and centrifuged for $10.0 \mathrm{~min}$ at 4000 r.p.m.

Assay of salicylic acid was carried out using spectrophotometer according to lqbal and Vaid (2009).

The supernatant from the both extractions in combined and $2.5 \mathrm{ml}$ of these extractions is diluted to $25.0 \mathrm{ml} \mathrm{A.d}$. in volumetric flask

$2.5 \mathrm{ml}$ extraction $+0.5 \mathrm{ml} \mathrm{FeCl} 35 \%+22.0 \mathrm{ml} \mathrm{A.d}$.

Absorbance of the sample was determined using a spectrophotometer set at 360 $\mathrm{nm}$.

\section{Statistical analysis}

Data were statistically analyzed by ANOVA, the analysis of variance to test the treatments effect on different measured parameters. Data were analysed using an ANOVA split split design, the differences between the different treatments 
combinations were tested using the Duncan's Multiple range method outlined by (Snedecor and Cochran, 1982).

\section{RESULTS}

\section{Mycorrhizal root length colonization}

The percentage of AM colonization was estimated after 45, 90 and 120 days old. Records of wheat plants, inoculated either with $G$. intraradices alone or with G. intraradices and Biotol significantly increased under all the tested levels of soil salinity, compared to un-inoculated plants. The highest percentages of AM colonization were attained after 90 days under $\mathrm{NPK}_{75 \%}$ and normal soil salinity being, 65.57 and 65.49 for cv. Sakha 93 and 58.56 and 60.39 for cv. Gemmeza 9, respectively. By increasing soil salinity, the percentage of AM colonization significantly decreased (Tables 1, 2 and 3).

\section{Shoot Na content}

Results presented in Table (4) showed that, the lowest values of $\mathrm{Na}$ contents $(\mathrm{mg} / \mathrm{kg})$ were observed under $\mathrm{EC} \leq 4 \mathrm{dSm}^{-1}$ for plants inoculated with $\mathrm{G}$. intraradices and Biotol (9.79 and $18.94 \mathrm{mg} / \mathrm{kg}$ ) under $\mathrm{NPK}_{100 \%}$ for Sakha 93 and Gemmeza 9, respectively. Un-inoculated plants recorded 18.75 and $26.86 \mathrm{mg} / \mathrm{kg}$ $\mathrm{Na}$ for both cultivars, respectively, under the same treatments. The same trends were noticed by increasing soil salinity levels.

\section{Chlorophyll index}

Chlorophyll index was significantly affected with soil salinity and levels of mineral fertilizers. Under soil salinity level $\leq 4 \mathrm{dSm}^{-1}$ the highest values of chlorophyll were 55.75 and 49.96 for plants inoculated with AM+Biotol under $\mathrm{NPK}_{100 \%}$ for the tested wheat cultivars; representing increase percentages 26.73 and $26.31 \%$ over uninoculated ones. No significant differences were observed between $\mathrm{NPK}_{75}$ and $\mathrm{NPK}_{100 \%}$ of the recommended dose of mineral fertilizers. The same trends were observed with increasing the soil salinity levels. Significant differences in chlorophyll contents were found between the wheat cultivars at soil salinity level 8-12 $\mathrm{dSm}^{-1}$. Sakha 93 recorded higher values of chlorophyll, compared to the Gemmeza 9 (Table 5).

\section{NPK uptake (kg/ha)}

Data in Tables $(6,7$ and 8 ) reveal that inoculation with the AM fungus and Biotol, significantly increased NPK uptake $(\mathrm{kg} / \mathrm{ha})$ when compared to uninoculated ones. Under salinity level $\leq 4 \mathrm{dSm}^{-1}$ the highest uptake values of $\mathrm{N}$ (Table 6) $\mathrm{P}$ (Table 7) $\mathrm{K}$ (Table 8) were recorded in case of plants inoculated with AM+Biotol under $\mathrm{NPK}_{100 \%}$ for both the tested cultivars. No significant differences were observed between $\mathrm{NPK}_{75}$ and $\mathrm{NPK}_{100 \%}$ mineral fertilizers. The same trends were observed with increasing the soil salinity levels. The NPK uptake values decreased under soil salinity level 8-12 dSm${ }^{-1}$. 
Table (1). Effect of wheat inoculation with Glomus intraradices and Biotol on the percentage of mycorrhizal root colonization after 45 days from planting in the presence of four levels of soil salinity (averages of the two seasons 2012/2013 and 2013/2014).

\begin{tabular}{|c|c|c|c|c|c|c|c|c|c|c|c|}
\hline Cultivars & $\begin{array}{l}\text { NPK } \\
\text { Levels }\end{array}$ & Un-inoc. & AM & Biotol & $A M+B$ & $\begin{array}{c}\text { Mean } \\
\text { of } \\
\text { NPK }\end{array}$ & $\begin{array}{c}\text { Mean } \\
\text { of } \\
\text { Cultiv. }\end{array}$ & Cultiv. & NPK & Inoc. & $\begin{array}{l}\text { Inoc.* } \\
\text { NPK }\end{array}$ \\
\hline \multicolumn{2}{|c|}{ Parameter } & \multicolumn{6}{|c|}{$\begin{array}{l}\text { Mycorrhizal root length colonization \% EC: } \\
\text { average } 2.8 \mathrm{dSm}^{-1}\end{array}$} & \multicolumn{4}{|c|}{ L.S.D.0.05 } \\
\hline \multirow{4}{*}{ Sakha 93} & $\mathrm{NPK}_{0 \%}$ & 0.00 & 14.94 & 2.24 & 16.31 & $\mathrm{NPK}_{0 \%}$ & & \multirow{8}{*}{ NS } & \multirow{8}{*}{$2.988^{*}$} & \multirow{8}{*}{$2.317^{* * *}$} & \multirow{8}{*}{ NS } \\
\hline & $\mathrm{NPK}_{50 \%}$ & 0.00 & 15.46 & 1.10 & 13.70 & $7.66 \mathrm{~b}$ & & & & & \\
\hline & $\mathrm{NPK}_{75 \%}$ & 1.10 & 21.68 & 2.19 & 23.49 & $\mathrm{NPK}_{50 \%}$ & $9.42 a$ & & & & \\
\hline & $\mathrm{NPK}_{100 \%}$ & 0.00 & 17.70 & 2.09 & 18.76 & $8.71 \mathrm{~b}$ & & & & & \\
\hline \multirow{4}{*}{ Gemmeza 9} & $\mathrm{NPK}_{0 \%}$ & 0.00 & 10.99 & 0.00 & 16.77 & $\mathrm{NPK}_{75 \%}$ & \multirow{4}{*}{$10.07 a$} & & & & \\
\hline & $\mathrm{NPK}_{50 \%}$ & 1.07 & 16.38 & 3.26 & 18.66 & $12.73 \mathrm{a}$ & & & & & \\
\hline & $\mathrm{NPK}_{75 \%}$ & 0.94 & 26.40 & 4.48 & 21.54 & $\mathrm{NPK}_{100 \%}$ & & & & & \\
\hline & $\mathrm{NPK}_{100 \%}$ & 1.06 & 17.06 & 3.32 & 19.16 & 9.89ab & & & & & \\
\hline \multicolumn{2}{|c|}{ Mean of Inoc. } & $0.52 b$ & $17.58 \mathrm{a}$ & $2.35 \mathrm{~b}$ & $18.55 a$ & & & & & & \\
\hline \multicolumn{2}{|c|}{ Parameter } & \multicolumn{6}{|c|}{$\begin{array}{c}\text { Mycorrhizal root length colonization \% EC: } \\
\text { average } 5.3 \mathrm{dSm}^{-1}\end{array}$} & \multirow{9}{*}{ NS } & & & \\
\hline \multirow{8}{*}{ Gemmeza 9} & $\mathrm{NPK}_{0 \%}$ & 0.00 & 5.35 & 0.95 & 6.99 & $\mathrm{NPK}_{0 \%}$ & \multirow{4}{*}{$7.28 \mathrm{a}$} & & \multirow{8}{*}{$1.813^{* \star *}$} & \multirow{8}{*}{$1.193^{* * *}$} & \multirow{8}{*}{$* \star *$} \\
\hline & $\mathrm{NPK}_{50 \%}$ & 0.19 & 15.42 & 0.00 & 13.68 & $3.29 \mathrm{c}$ & & & & & \\
\hline & $\mathrm{NPK}_{75 \%}$ & 0.00 & 19.68 & 2.19 & 22.96 & $\mathrm{NPK}_{50 \%}$ & & & & & \\
\hline & $\mathrm{NPK}_{100 \%}$ & 1.08 & 11.98 & 1.71 & 14.25 & $6.57 \mathrm{~b}$ & & & & & \\
\hline & $\mathrm{NPK}_{0 \%}$ & 0.00 & 6.06 & 0.00 & 6.96 & $\mathrm{NPK}_{75 \%}$ & & & & & \\
\hline & $\mathrm{NPK}_{50 \%}$ & 1.10 & 9.18 & 0.00 & 13.00 & $11.24 \mathrm{a}$ & 601 a & & & & \\
\hline & $\mathrm{NPK}_{75 \%}$ & 1.07 & 19.24 & 2.19 & 22.57 & $\mathrm{NPK}_{100 \%}$ & $0.91 \mathrm{a}$ & & & & \\
\hline & $\mathrm{NPK}_{100 \%}$ & 1.05 & 12.85 & 1.07 & 14.16 & $7.27 \mathrm{~b}$ & & & & & \\
\hline \multicolumn{2}{|c|}{ Mean of Inoc. } & $0.56 \mathrm{c}$ & $12.47 \mathrm{~b}$ & $1.01 \mathrm{c}$ & $14.32 a$ & & & & & & \\
\hline \multicolumn{2}{|c|}{ Parameter } & \multicolumn{6}{|c|}{$\begin{array}{l}\text { Mycorrhizal root length colonization \% EC: } \\
\text { average } 7.6 \mathrm{dSm}^{-1}\end{array}$} & \multirow{9}{*}{ NS } & & & \\
\hline & $\mathrm{NPK}_{0 \%}$ & 0.00 & 0.88 & 0.00 & 2.22 & $\mathrm{NPK}_{0 \%}$ & & & & & \\
\hline Sakha 93 & $\mathrm{NPK}_{50 \%}$ & 0.22 & 1.26 & 0.67 & 2.57 & $0.80 \mathrm{~b}$ & 1937 & & & & \\
\hline sakna ys & $\mathrm{NPK}_{75 \%}$ & 0.00 & 4.05 & 2.01 & 5.56 & $\mathrm{NPK}_{50 \%}$ & $1.93 a$ & & & & \\
\hline & $\mathrm{NPK}_{100 \%}$ & 1.11 & 4.33 & 1.60 & 4.43 & $1.49 \mathrm{~b}$ & & & $0.941^{* * *}$ & $0.604^{* * *}$ & $\star \star \star *$ \\
\hline & $\mathrm{NPK}_{0 \%}$ & 0.00 & 1.11 & 0.00 & 2.23 & $\mathrm{NPK}_{75 \%}$ & & & 0.941 & 0.604 & \\
\hline & $\mathrm{NPK}_{50 \%}$ & 0.00 & 1.67 & 1.61 & 3.95 & $3.21 \mathrm{a}$ & & & & & \\
\hline Gemmeza 9 & $\mathrm{NPK}_{75 \%}$ & 0.00 & 6.37 & 1.67 & 6.05 & $\mathrm{NPK}_{100 \%}$ & $2.11 \mathrm{a}$ & & & & \\
\hline & $\mathrm{NPK}_{100 \%}$ & 0.51 & 2.15 & 2.22 & 4.31 & $2.58 \mathrm{a}$ & & & & & \\
\hline Mean of & Inoc. & $0.23 d$ & $2.73 b$ & $1.22 \mathrm{c}$ & $3.91 \mathrm{a}$ & & & & & & \\
\hline Parame & eter & Myco & orrhizal & $\begin{array}{l}\text { oot leng } \\
\text { iverage } 1\end{array}$ & $\begin{array}{l}\text { h colon } \\
0.5 \mathrm{dSm}\end{array}$ & ization \% & EC: & & & & \\
\hline & $\mathrm{NPK}_{0 \%}$ & 0.00 & 0.58 & 0.00 & 1.18 & $\mathrm{NPK}_{0 \%}$ & & & & & \\
\hline & $\mathrm{NPK}_{50 \%}$ & 0.22 & 1.19 & 0.59 & 2.99 & $0.59 \mathrm{c}$ & & & & & \\
\hline Sakna 93 & $\mathrm{NPK}_{75 \%}$ & 0.28 & 3.61 & 1.18 & 5.16 & $\mathrm{NPK}_{50 \%}$ & 1.70a & & & & \\
\hline & $\mathrm{NPK}_{100 \%}$ & 0.61 & 3.60 & 1.23 & 4.82 & $1.22 \mathrm{bc}$ & & & & & \\
\hline & $\mathrm{NPK}_{0 \%}$ & 0.00 & 1.17 & 0.00 & 1.78 & $\mathrm{NPK}_{75 \%}$ & & NS & $0.683^{n}$ & $0.564^{\pi x}$ & NS \\
\hline & $\mathrm{NPK}_{50 \%}$ & 0.00 & 1.77 & 0.59 & 2.37 & $2.1 \mathrm{a}$ & & & & & \\
\hline Gemmeza 9 & $\mathrm{NPK}_{75 \%}$ & 0.00 & 2.98 & 0.59 & 3.00 & $\mathrm{NPK}_{100 \%}$ & $1.08 \mathrm{a}$ & & & & \\
\hline & $\mathrm{NPK}_{100 \%}$ & 0.00 & 1.20 & 0.00 & 1.79 & $1.66 \mathrm{ab}$ & & & & & \\
\hline Mean of & Inoc. & $0.14 \mathrm{c}$ & $2.01 \mathrm{~b}$ & $0.522 \mathrm{c}$ & $2.89 a$ & & & & & & \\
\hline
\end{tabular}


Table (2). Effect of wheat inoculation with Glomus intraradices and Biotol the percentage of mycorrhizal root colonization after 90 days from planting in the presence of four levels of soil salinity (averages of the two seasons 2012/2013 and 2013/2014).

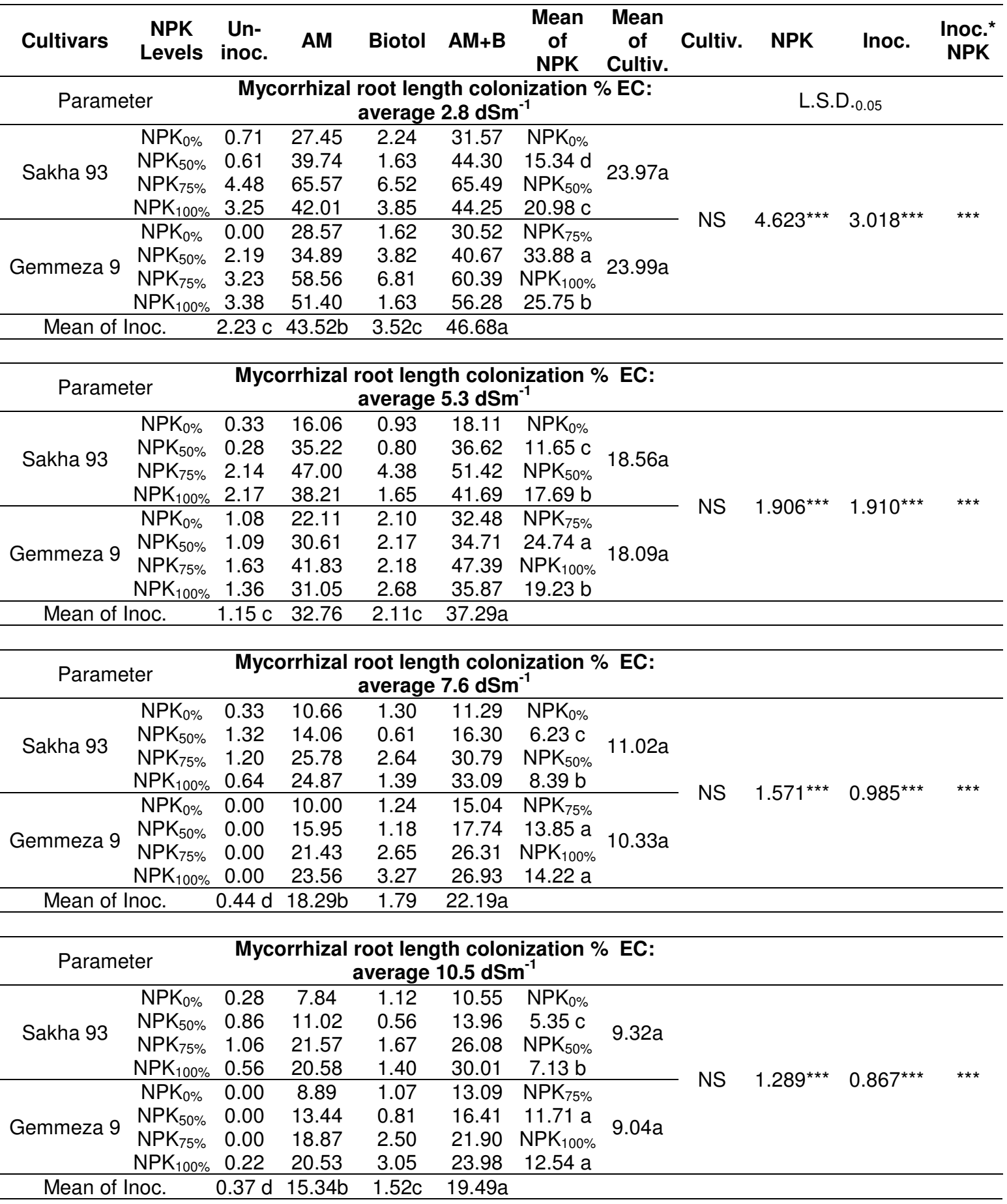


Table (3). Effect of wheat inoculation with Glomus intraradices and Biotol on the percentage of mycorrhizal root colonization after 120 days from planting in the presence of four levels of soil salinity (averages of the two seasons 2012/2013 and 2013/2014)

\begin{tabular}{|c|c|c|c|c|c|c|c|c|c|c|c|}
\hline Cultivars & $\begin{array}{l}\text { NPK } \\
\text { Levels }\end{array}$ & $\begin{array}{l}\text { Un- } \\
\text { inoc. }\end{array}$ & AM & Biotol & $A M+B$ & $\begin{array}{l}\text { Mean } \\
\text { of } \\
\text { NPK }\end{array}$ & $\begin{array}{c}\text { Mean } \\
\text { of } \\
\text { Cultiv. }\end{array}$ & Cultiv. & NPK & Inoc. & $\begin{array}{l}\text { Inoc.* } \\
\text { NPK }\end{array}$ \\
\hline \multicolumn{2}{|c|}{ Parameter } & \multicolumn{6}{|c|}{$\begin{array}{l}\text { Mycorrhizal root length colonization \% EC: } \\
\text { average } 2.8 \mathrm{dSm}^{-1}\end{array}$} & \multicolumn{4}{|c|}{ L.S.D.0.05 } \\
\hline Sakha 93 & $\begin{array}{l}\mathrm{NPK}_{0 \%} \\
\mathrm{NPK}_{50 \%} \\
\mathrm{NPK}_{75 \%} \\
\mathrm{NPK}_{100 \%}\end{array}$ & $\begin{array}{l}1.41 \\
2.31 \\
5.58 \\
4.34\end{array}$ & $\begin{array}{l}31.80 \\
54.02 \\
78.31 \\
62.06\end{array}$ & $\begin{array}{c}5.55 \\
3.28 \\
10.91 \\
7.68\end{array}$ & $\begin{array}{l}33.41 \\
56.04 \\
82.09 \\
67.64\end{array}$ & $\begin{array}{l}\mathrm{NPK}_{0 \%} \\
18.36 \mathrm{~d} \\
\mathrm{NPK}_{50 \%} \\
27.04 \mathrm{c}\end{array}$ & $31.65 a$ & \multirow[b]{2}{*}{ NS } & \multirow[b]{2}{*}{$4.486^{\star \star *}$} & \multirow[b]{2}{*}{$2.555^{\star \star \star}$} & \multirow[b]{2}{*}{$* * *$} \\
\hline Gemmeza 9 & $\begin{array}{l}\mathrm{NPK}_{0 \%} \\
\mathrm{NPK}_{50 \%} \\
\mathrm{NPK}_{75 \%} \\
\mathrm{NPK}_{100 \%}\end{array}$ & $\begin{array}{l}0.55 \\
3.27 \\
5.35 \\
2.28\end{array}$ & $\begin{array}{l}34.06 \\
43.63 \\
69.93 \\
55.90\end{array}$ & $\begin{array}{c}5.32 \\
5.46 \\
10.21 \\
7.14\end{array}$ & $\begin{array}{l}34.75 \\
48.33 \\
70.17 \\
61.93\end{array}$ & $\begin{array}{l}\mathrm{NPK}_{75 \%} \\
41.57 \mathrm{a} \\
\mathrm{NPK}_{100 \%} \\
33.62 \mathrm{~b}\end{array}$ & $28.64 a$ & & & & \\
\hline \multicolumn{2}{|c|}{ Mean of Inoc. } & $3.14 d$ & $53.71 \mathrm{~b}$ & $6.95 c$ & $56.79 a$ & & & & & & \\
\hline \multicolumn{2}{|c|}{ Parameter } & \multicolumn{6}{|c|}{$\begin{array}{c}\begin{array}{c}\text { Mycorrhizal root length colonization \% EC: } \\
\text { average } 5.3 \mathrm{dSm}^{-1}\end{array}\end{array}$} & \multirow{3}{*}{ NS } & \multirow{3}{*}{$4.529^{* \star *}$} & \multirow{3}{*}{$3.463^{\star \star *}$} & \multirow{3}{*}{$* * *$} \\
\hline \multirow[b]{2}{*}{ Gemmeza 9} & $\begin{array}{l}\mathrm{NPK}_{0 \%} \\
\mathrm{NPK}_{50 \%} \\
\mathrm{NPK}_{75 \%} \\
\mathrm{NPK}_{100 \%}\end{array}$ & $\begin{array}{l}1.09 \\
1.72 \\
3.18 \\
1.91\end{array}$ & $\begin{array}{l}22.48 \\
40.71 \\
55.75 \\
35.04\end{array}$ & $\begin{array}{l}1.84 \\
3.24 \\
7.67 \\
2.76\end{array}$ & $\begin{array}{l}26.01 \\
47.96 \\
60.16 \\
48.28\end{array}$ & $\begin{array}{l}\mathrm{NPK}_{0 \%} \\
14.99 \mathrm{c} \\
\mathrm{NPK}_{50 \%} \\
21.74 \mathrm{~b}\end{array}$ & $22.48 a$ & & & & \\
\hline & $\begin{array}{l}\mathrm{NPK}_{0 \%} \\
\mathrm{NPK}_{50 \%} \\
\mathrm{NPK}_{75 \%} \\
\mathrm{NPK}_{100 \%}\end{array}$ & $\begin{array}{l}3.04 \\
2.16 \\
4.32 \\
2.94\end{array}$ & $\begin{array}{l}27.01 \\
33.66 \\
46.06 \\
33.19 \\
\end{array}$ & $\begin{array}{l}2.87 \\
4.29 \\
5.44 \\
5.34\end{array}$ & $\begin{array}{l}35.57 \\
40.22 \\
47.36 \\
50.04\end{array}$ & $\begin{array}{l}\mathrm{NPK}_{75 \%} \\
28.74 \mathrm{a} \\
\mathrm{NPK}_{100 \%} \\
22.43 \mathrm{~b}\end{array}$ & $21.47 a$ & & & & \\
\hline \multicolumn{2}{|c|}{ Mean of Inoc. } & $2.55 \mathrm{c}$ & $36.74 b$ & $4.18 \mathrm{c}$ & $44.45 a$ & & & & & & \\
\hline \multicolumn{2}{|c|}{ Parameter } & \multicolumn{6}{|c|}{$\begin{array}{c}\text { Mycorrhizal root length colonization \% EC: } \\
\text { average } 7.6 \mathrm{dSm}^{-1}\end{array}$} & \multirow{3}{*}{ NS } & \multirow{3}{*}{$1.340^{\star * *}$} & \multirow{3}{*}{$1.308^{* * *}$} & \multirow{3}{*}{$* \star \star$} \\
\hline \multirow[b]{2}{*}{ Gemmeza 9} & $\begin{array}{l}\mathrm{NPK}_{0 \%} \\
\mathrm{NPK}_{50 \%} \\
\mathrm{NPK}_{75 \%} \\
\mathrm{NPK}_{100 \%}\end{array}$ & $\begin{array}{l}0.39 \\
0.44 \\
1.29 \\
0.67\end{array}$ & $\begin{array}{l}13.64 \\
18.21 \\
29.29 \\
28.68\end{array}$ & $\begin{array}{l}0.89 \\
0.89 \\
1.82 \\
2.28\end{array}$ & $\begin{array}{l}17.76 \\
21.11 \\
36.17 \\
35.61\end{array}$ & $\begin{array}{c}\mathrm{NPK}_{0 \%} \\
8.96 \mathrm{c} \\
\mathrm{NPK}_{50 \%} \\
11.06 \mathrm{~b}\end{array}$ & $13.07 a$ & & & & \\
\hline & $\begin{array}{l}\mathrm{NPK}_{0 \%} \\
\mathrm{NPK}_{50 \%} \\
\mathrm{NPK}_{75 \%} \\
\mathrm{NPK}_{100 \%}\end{array}$ & $\begin{array}{l}0.81 \\
0.56 \\
1.69 \\
1.91 \\
\end{array}$ & $\begin{array}{l}16.56 \\
22.17 \\
27.66 \\
26.09 \\
\end{array}$ & $\begin{array}{l}1.64 \\
1.03 \\
4.44 \\
2.55 \\
\end{array}$ & $\begin{array}{l}20.04 \\
24.04 \\
30.18 \\
33.16\end{array}$ & $\begin{array}{c}\mathrm{NPK}_{75 \%} \\
16.57 \mathrm{a} \\
\mathrm{NPK}_{100 \%} \\
16.37 \mathrm{a}\end{array}$ & $13.41 \mathrm{a}$ & & & & \\
\hline \multicolumn{2}{|c|}{ Mean of Inoc. } & $0.97 \mathrm{c}$ & $22.78 b$ & $1.94 \mathrm{c}$ & $27.26 \mathrm{a}$ & & & & & & \\
\hline \multicolumn{2}{|c|}{ Parameter } & \multicolumn{6}{|c|}{$\begin{array}{c}\text { Mycorrhizal root length colonization \% EC: } \\
\text { average } 10.5 \mathrm{dSm}^{-1}\end{array}$} & \multirow[b]{3}{*}{ NS } & \multirow{3}{*}{$1.583^{\star \star \star}$} & & \\
\hline Sakha 93 & $\begin{array}{l}\mathrm{NPK}_{0 \%} \\
\mathrm{NPK}_{50 \%} \\
\mathrm{NPK}_{75 \%} \\
\mathrm{NPK}_{100 \%}\end{array}$ & $\begin{array}{l}0.83 \\
1.20 \\
0.82 \\
1.10\end{array}$ & $\begin{array}{l}11.46 \\
14.95 \\
31.35 \\
27.97\end{array}$ & $\begin{array}{l}2.28 \\
0.59 \\
2.04 \\
2.40\end{array}$ & $\begin{array}{l}14.24 \\
18.56 \\
31.23 \\
33.91 \\
\end{array}$ & $\begin{array}{c}\mathrm{NPK}_{0 \%} \\
7.76 \mathrm{~b} \\
\mathrm{NPK}_{50 \%} \\
9.31 \mathrm{~b}\end{array}$ & $12.18 a$ & & & & \\
\hline Gemmeza 9 & $\begin{array}{l}\mathrm{NPK}_{0 \%} \\
\mathrm{NPK}_{50 \%} \\
\mathrm{NPK}_{75 \%} \\
\mathrm{NPK}_{100 \%}\end{array}$ & $\begin{array}{l}0.22 \\
0.58 \\
1.18 \\
1.35\end{array}$ & $\begin{array}{l}15.30 \\
17.81 \\
25.09 \\
26.08\end{array}$ & $\begin{array}{l}1.24 \\
0.59 \\
2.38 \\
2.42\end{array}$ & $\begin{array}{l}16.50 \\
20.17 \\
27.13 \\
28.57\end{array}$ & $\begin{array}{c}\mathrm{NPK}_{75 \%} \\
15.15 \mathrm{a} \\
\mathrm{NPK}_{100 \%} \\
15.42 \mathrm{a}\end{array}$ & $11.63 a$ & & & $1.110^{\star \star \star}$ & 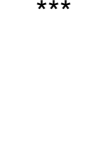 \\
\hline Mean of & Inoc. & $0.91 \mathrm{c}$ & $21.25 b$ & $1.69 c$ & $23.79 a$ & & & & & & \\
\hline
\end{tabular}


Table (4). Effect of wheat inoculation with Glomus intraradices and Biotol on Shoot $\mathrm{Na}$ content $(\mathrm{mg} / \mathrm{kg})$ in the presence of four levels of soil salinity (averages of the two seasons 2012/2013 and 2013/2014)

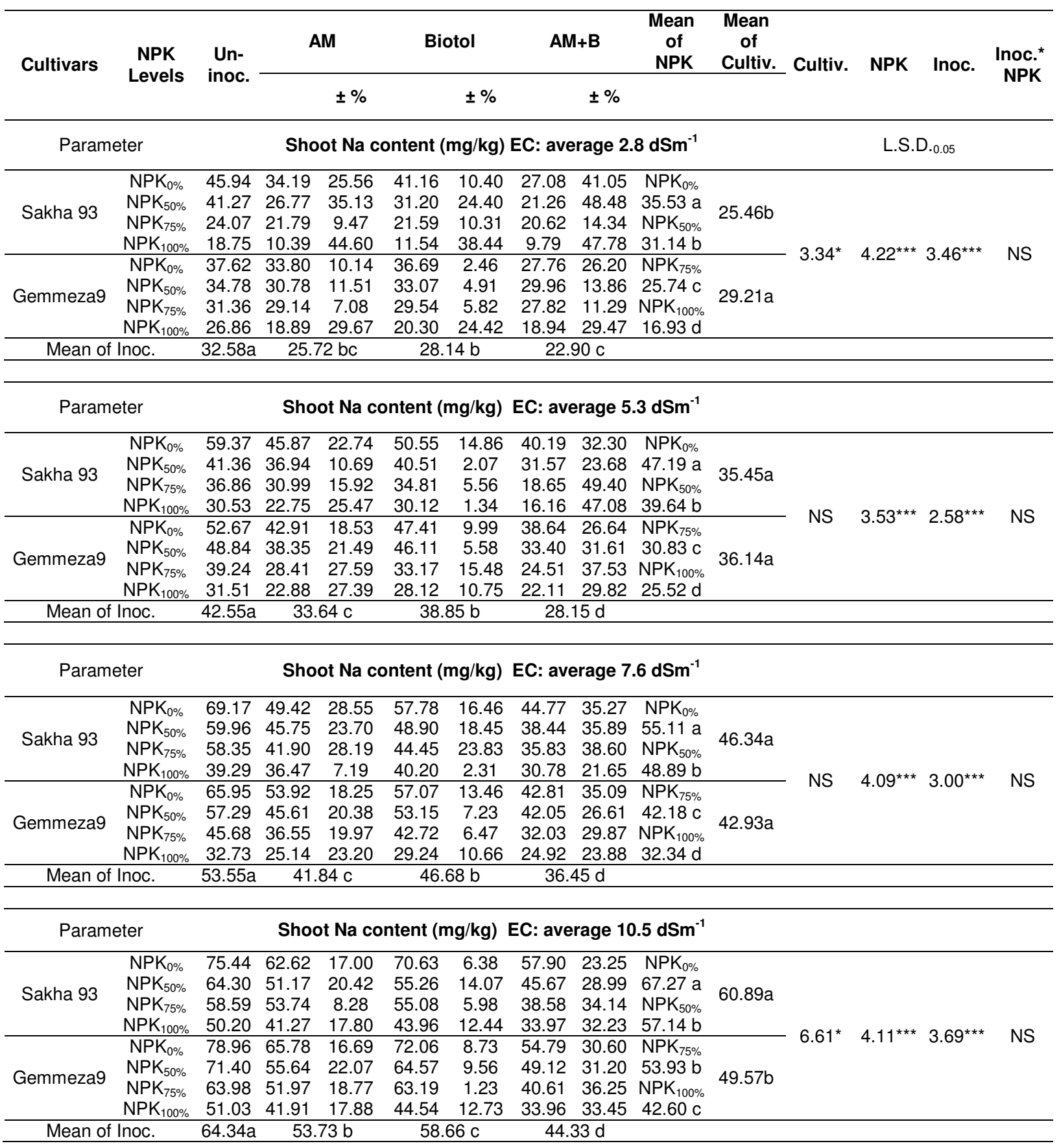

$\pm \%$ Increase or decrease to uninoculated (control) plants 
Table (5). Effect of wheat inoculation with Glomus intraradices and Biotol on chlorophyll index (SPAD) in the presence of four levels of soil salinity (averages of the two seasons 2012/2013 and 2013/2014)

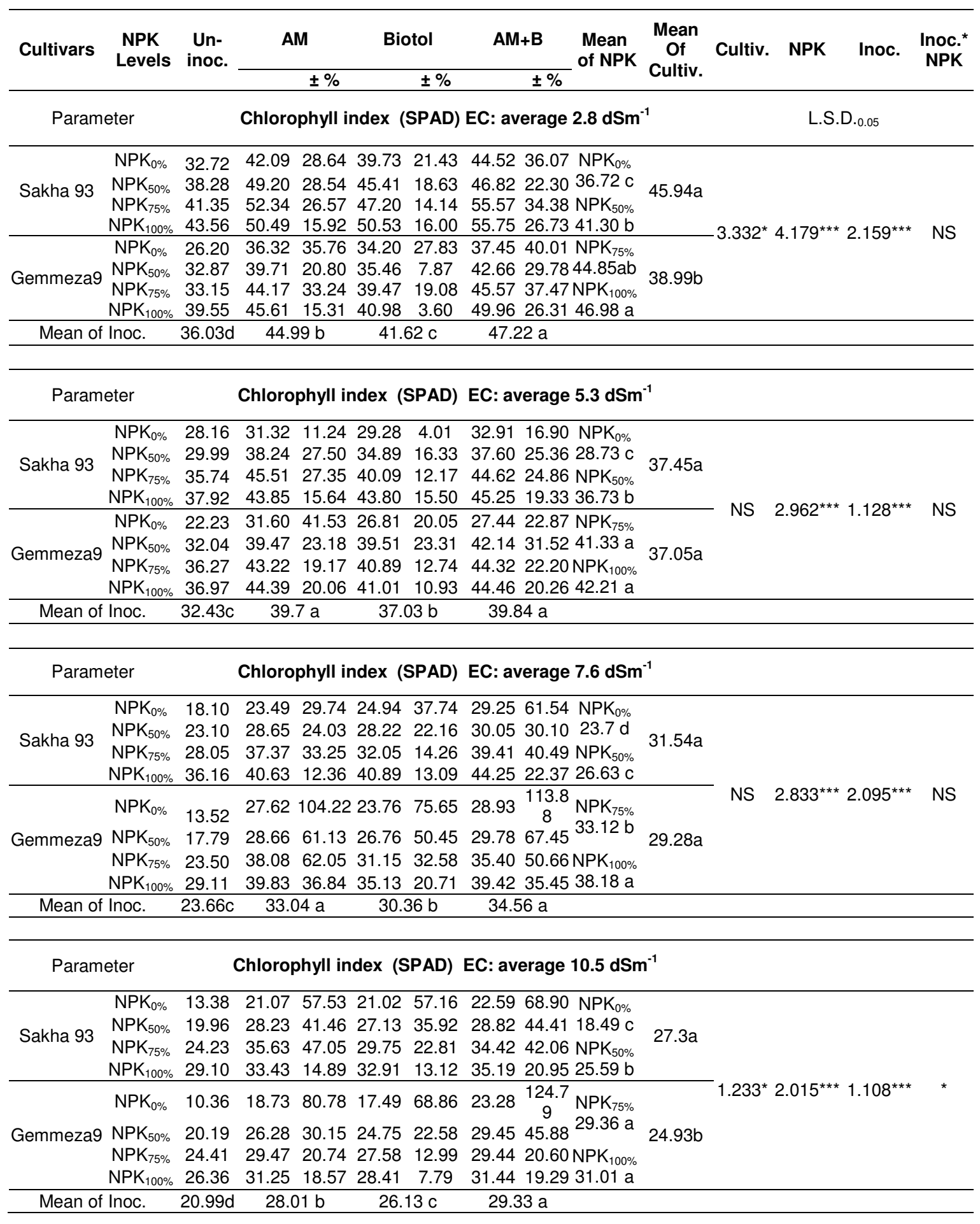

$\pm \%$ Increase or decrease to uninoculated (control) plants 
Table (6). Effect of wheat inoculation with Glomus intraradices and Biotol on
$\mathrm{N}$ uptake (kg/ha) in the presence of four levels of soil salinity
(averages of the two seasons $2012 / 2013$ and 2013/2014)

\begin{tabular}{|c|c|c|c|c|c|c|c|c|c|c|c|c|c|c|}
\hline \multirow[t]{2}{*}{ Cultivars } & \multirow[t]{2}{*}{$\begin{array}{c}\text { NPK } \\
\text { Levels }\end{array}$} & \multirow[t]{2}{*}{$\begin{array}{l}\text { Un- } \\
\text { inoc. }\end{array}$} & \multicolumn{2}{|c|}{ AM } & Biotol & & M+B & & $\begin{array}{l}\text { lean } \\
\text { of } \\
\text { NPK }\end{array}$ & \multirow{2}{*}{$\begin{array}{c}\text { Mean } \\
\text { of } \\
\text { Cultiv. }\end{array}$} & \multirow{2}{*}{ Cultiv. } & \multirow[t]{2}{*}{ NPK } & \multirow[t]{2}{*}{ Inoc. } & \multirow[t]{2}{*}{$\begin{array}{c}\text { Inoc. } \\
\text { NPK }\end{array}$} \\
\hline & & & & $\pm \%$ & & $\pm \%$ & & $\pm \%$ & & & & & & \\
\hline \multicolumn{3}{|c|}{ Parameter } & \multicolumn{7}{|c|}{ N Uptake (kg/ha) EC: average $2.8 \mathrm{dSm}^{-1}$} & & \multicolumn{4}{|c|}{ L.S.D.0.05 } \\
\hline Sakha 93 & $\begin{array}{l}\mathrm{NPK}_{0 \%} \\
\mathrm{NPK}_{50 \%} \\
\mathrm{NPK}_{75 \%} \\
\mathrm{NPK}_{100 \%}\end{array}$ & $\begin{array}{l}14.908 \\
20.692 \\
41.419 \\
64.175\end{array}$ & $\begin{array}{c}37.525 \\
58.805 \\
99.613 \\
126.311\end{array}$ & $\begin{array}{c}151.71 \\
184.19 \\
140.50 \\
96.82\end{array}$ & $\begin{array}{l}30.492 \\
48.179 \\
77.232 \\
92.478\end{array}$ & $\begin{array}{c}104.53 \\
132.84 \\
86.47 \\
44.10\end{array}$ & $\begin{array}{c}43.428 \\
61.231 \\
105.178 \\
116.433\end{array}$ & $\begin{array}{c}191.30 \\
195.92 \\
153.94 \\
81.43\end{array}$ & $\begin{array}{l}\mathrm{NPK}_{0 \%} \\
29.47 \mathrm{~d} \\
\mathrm{NPK}_{50 \%} \\
54.41 \mathrm{c}\end{array}$ & $65.49 a$ & \multirow{3}{*}{ NS } & \multirow{2}{*}{$5.519^{* * *}$} & \multirow{2}{*}{$7.09^{* * *}$} & \multirow{2}{*}{ ** } \\
\hline Gemmeza9 & $\begin{array}{l}\mathrm{NPK}_{0 \%} \\
\mathrm{NPK}_{50 \%} \\
\mathrm{NPK}_{75 \%} \\
\mathrm{NPK}_{100 \%}\end{array}$ & $\begin{array}{c}13.72 \\
23.570 \\
34.903 \\
59.886\end{array}$ & $\begin{array}{c}41.813 \\
62.426 \\
90.744 \\
118.167\end{array}$ & $\begin{array}{c}204.72 \\
164.85 \\
159.99 \\
97.32\end{array}$ & $\begin{array}{l}28.380 \\
66.095 \\
65.977 \\
95.000\end{array}$ & $\begin{array}{c}106.82 \\
180.42 \\
89.03 \\
58.63\end{array}$ & $\begin{array}{c}32.982 \\
77.786 \\
107.354 \\
130.015\end{array}$ & $\begin{array}{l}140.36 \\
230.02 \\
207.58 \\
117.10\end{array}$ & $\begin{array}{c}\mathrm{NPK}_{75 \%} \\
77.8 \mathrm{~b} \\
\mathrm{NPK}_{100 \%} \\
99.47 \mathrm{a}\end{array}$ & \multirow[t]{2}{*}{$65.08 \mathrm{a}$} & & & & \\
\hline Mean of & Inoc. & $32.39 c$ & 81.4 & & $62.98 \mathrm{~b}$ & & $84.3 \mathrm{a}$ & & & & & & & \\
\hline
\end{tabular}

Parameter

\begin{tabular}{|c|c|c|c|c|c|c|c|c|c|c|c|c|c|}
\hline \multirow{4}{*}{ Sakha 93} & $\mathrm{NPK}_{0 \%}$ & 6.384 & 11.980 & 87.67 & 16.987 & 166.10 & 22.145 & 246.90 & $\mathrm{NPK}_{0 \%}$ & & \multirow{8}{*}{ NS } & \multirow{9}{*}{$4.945^{\star \star \star} \quad 3.414^{\star \star \star}$} & \multirow{8}{*}{ *** } \\
\hline & $\mathrm{NPK}_{50 \%}$ & 11.705 & 33.575 & 186.84 & 31.677 & 170.62 & 41.977 & 258.61 & $12.04 \mathrm{~d}$ & 35352 & & & \\
\hline & $\mathrm{NPK}_{75 \%}$ & 19.429 & 52.407 & 169.74 & 38.678 & 99.07 & 50.151 & 158.12 & $\mathrm{NPK}_{50 \%}$ & $35.35 \mathrm{a}$ & & & \\
\hline & $\mathrm{NPK}_{100 \%}$ & 40.466 & 70.250 & 73.60 & 52.723 & 30.29 & 75.119 & 85.63 & $24.52 \mathrm{c}$ & & & & \\
\hline \multirow{4}{*}{ Gemmeza9 } & $\mathrm{NPK}_{0 \%}$ & 5.092 & 9.626 & 89.02 & 8.129 & 59.64 & 15.963 & 213.46 & $\mathrm{NPK}_{75 \%}$ & \multirow{4}{*}{$28.08 \mathrm{a}$} & & & \\
\hline & $\mathrm{NPK}_{50 \%}$ & 10.202 & 24.933 & 144.39 & 17.944 & 75.88 & 24.176 & 136.96 & $38.07 \mathrm{~b}$ & & & & \\
\hline & $\mathrm{NPK}_{75 \%}$ & 16.960 & 43.089 & 154.05 & 29.901 & 76.30 & 53.973 & 218.23 & $\mathrm{NPK}_{100 \%}$ & & & & \\
\hline & $\mathrm{NPK}_{100 \%}$ & 25.615 & 53.581 & 109.18 & 46.544 & 81.70 & 63.513 & 147.95 & $52.22 \mathrm{a}$ & & & & \\
\hline Mean of & Inoc. & $15.73 d$ & 37.4 & $3 \mathrm{~b}$ & $30.32 \mathrm{c}$ & & $43.38 \mathrm{a}$ & & & & & & \\
\hline
\end{tabular}

Parameter

N Uptake (kg/ha) EC: average $7.6 \mathrm{dSm}^{-1}$

\begin{tabular}{|c|c|c|c|c|c|c|c|c|c|c|c|c|c|}
\hline \multirow{4}{*}{ Sakha 93} & $\mathrm{NPK}_{0 \%}$ & 2.208 & 6.735 & 205.04 & 4.630 & 109.72 & 8.020 & 263.27 & $\mathrm{NPK}_{0 \%}$ & \multirow{4}{*}{$16.32 a$} & \multirow{9}{*}{ NS } & \multirow{9}{*}{$2.716^{\star \star \star} 1.863^{\star \star \star}$} & \multirow{8}{*}{ *** } \\
\hline & $\mathrm{NPK}_{50 \%}$ & 5.323 & 14.505 & 172.48 & 13.915 & 161.39 & 15.887 & 198.44 & $5.06 \mathrm{~d}$ & & & & \\
\hline & $\mathrm{NPK}_{75 \%}$ & 10.791 & 23.131 & 114.34 & 17.576 & 62.87 & 27.374 & 153.66 & $\mathrm{NPK}_{50 \%}$ & & & & \\
\hline & $\mathrm{NPK}_{100 \%}$ & 16.238 & 39.148 & 141.09 & 24.454 & 50.60 & 41.956 & 158.38 & $10.49 \mathrm{c}$ & & & & \\
\hline \multirow{4}{*}{ Gemmeza9 } & $\mathrm{NPK}_{0 \%}$ & 2.549 & 5.950 & 133.45 & 4.715 & 84.98 & 7.835 & 207.42 & $\mathrm{NPK}_{75 \%}$ & \multirow{4}{*}{$14.83 a$} & & & \\
\hline & $\mathrm{NPK}_{50 \%}$ & 3.874 & 12.526 & 223.30 & 7.124 & 83.87 & 13.756 & 255.04 & $19.21 \mathrm{~b}$ & & & & \\
\hline & $\mathrm{NPK}_{75 \%}$ & 9.804 & 28.953 & 195.31 & 16.953 & 72.92 & 28.802 & 193.77 & $\mathrm{NPK}_{100 \%}$ & & & & \\
\hline & $\mathrm{NPK}_{100 \%}$ & 14.817 & 32.122 & 116.79 & 20.687 & 39.61 & 36.504 & 146.36 & $27.53 \mathrm{a}$ & & & & \\
\hline Mean of & Inoc. & $5.64 \mathrm{~d}$ & 20.3 & $8 \mathrm{~b}$ & $13.76 \mathrm{c}$ & & $22.52 a$ & & & & & & \\
\hline
\end{tabular}

Parameter

N Uptake (kg/ha) EC: average $10.5 \mathrm{dSm}^{-1}$

\begin{tabular}{|c|c|c|c|c|c|c|c|c|c|c|c|c|c|}
\hline \multirow{4}{*}{ Sakha 93} & $\mathrm{NPK}_{0 \%}$ & 1.464 & 2.025 & 38.34 & 1.890 & 29.14 & 4.703 & 221.33 & $\mathrm{NPK}_{0 \%}$ & & \multirow{9}{*}{ NS } & \multirow{9}{*}{$2.695^{\star \star \star} \quad 1.599^{\star \star \star}$} & \multirow{8}{*}{ ** } \\
\hline & $\mathrm{NPK}_{50 \%}$ & 2.600 & 5.565 & 114.05 & 6.596 & 153.71 & 8.907 & 242.58 & $2.35 d$ & 8923 & & & \\
\hline & $\mathrm{NPK}_{75 \%}$ & 3.570 & 13.680 & 283.16 & 9.593 & 168.67 & 18.917 & 429.81 & $\mathrm{NPK}_{50 \%}$ & & & & \\
\hline & $\mathrm{NPK}_{100 \%}$ & 6.827 & 19.416 & 184.00 & 14.510 & 112.24 & 23.396 & 242.21 & $6.95 \mathrm{c}$ & & & & \\
\hline \multirow{5}{*}{ Gemmeza9 } & $\mathrm{NPK}_{0 \%}$ & 1.517 & 2.972 & 95.93 & 1.832 & 20.77 & 4.381 & 188.87 & $\mathrm{NPK}_{75 \%}$ & \multirow{4}{*}{$8.41 a$} & & & \\
\hline & $\mathrm{NPK}_{50 \%}$ & 2.494 & 10.724 & 330.02 & 5.658 & 126.88 & 13.075 & 424.27 & $10.76 \mathrm{~b}$ & & & & \\
\hline & $\mathrm{NPK}_{75 \%}$ & 4.290 & 13.974 & 225.73 & 8.622 & 100.97 & 13.423 & 212.88 & $\mathrm{NPK}_{100 \%}$ & & & & \\
\hline & $\mathrm{NPK}_{100 \%}$ & 6.065 & 16.226 & 167.53 & 12.288 & 102.61 & 18.056 & 197.69 & $14.59 \mathrm{a}$ & & & & \\
\hline & Inoc. & $3.35 d$ & 10.5 & $7 \mathrm{~b}$ & $7.62 \mathrm{c}$ & & $13.11 \mathrm{a}$ & & & & & & \\
\hline
\end{tabular}

$\pm \%$ Increase or decrease to uninoculated (control) plants 


\section{Table (7). Effect of wheat inoculation with Glomus intraradices and Biotol on $P$ uptake $(\mathrm{kg} / \mathrm{ha})$ in the presence of four levels of soil salinity (averages of the two seasons 2012/2013 and 2013/2014)}

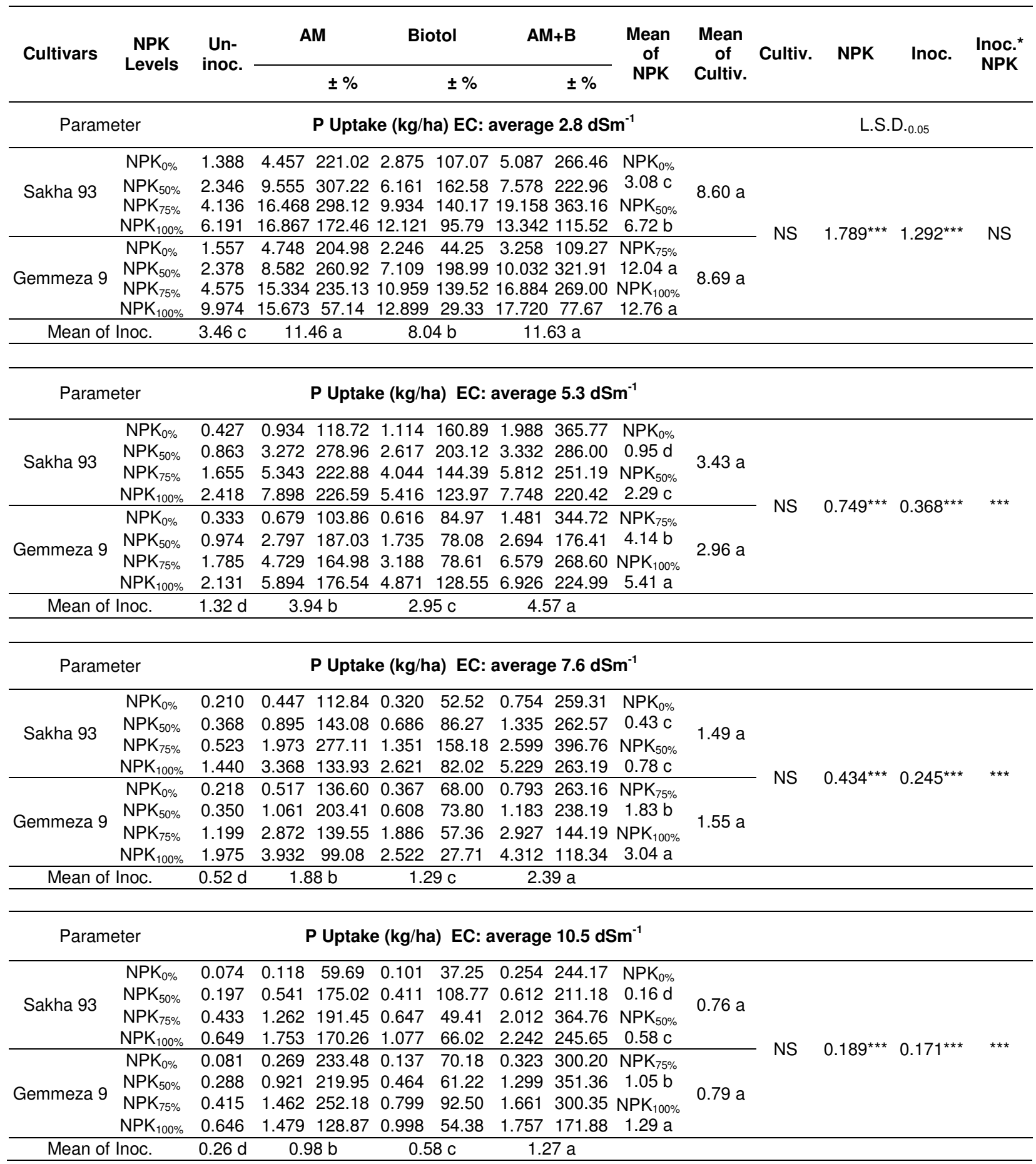

$\pm \%$ Increase or decrease to uninoculated (control) plants 
Table (8). Effect of wheat inoculation with Glomus intraradices and Biotol on $\mathrm{K}$ uptake $(\mathrm{kg} / \mathrm{ha})$ in the presence of four levels of soil salinity (averages of the two seasons 2012/2013 and 2013/2014)

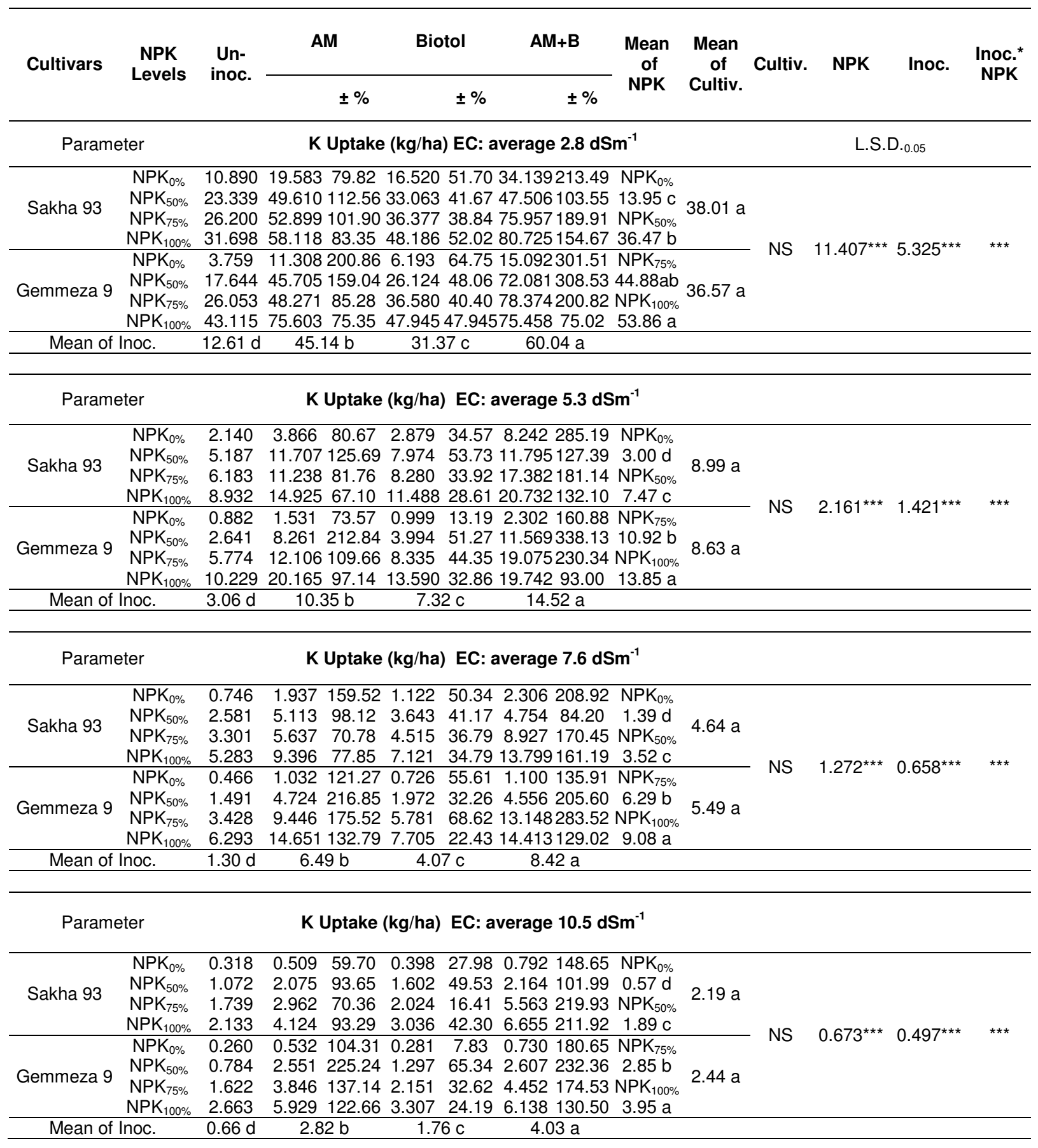

$\pm \%$ Increase or decrease to uninoculated (control) plants 


\section{0 grain weight}

Results presented in Table (9) showed that the highest value of 1000 grain weight $(\mathrm{g})$ was obtained from Gemmeza 9 plants inoculated with $\mathrm{G}$. intraradices $(54.59 \mathrm{~g})$ under soil salinity level $\leq 4 \mathrm{dSm}^{-1}$ and $\mathrm{NPK}_{75 \%}$. No significant differences were observed between $\mathrm{NPK}_{75}$ and $\mathrm{NPK}_{100 \%}$ mineral fertilizers. At soil salinity $8-$ $12 \mathrm{dSm}^{-1}$, the 1000 grain weight were 40.92 and $35.98 \mathrm{~g}$ for plants inoculated with AM+Biotol under $\mathrm{NPK}_{100 \%}$ for Sakha 93 and Gemmeza 9, respectively.

\section{Grain yield (t/ha)}

Results presented in Table (10) indicated that, grain yield due to dual inoculation with Glomus intraradices and Biotol resulted the maximum yield of grain (6.723 t/ha) under soil salinity level $\leq 4 \mathrm{dSm}^{-1}$ and $\mathrm{NPK}_{100 \%}$ in case of Gemmeza 9. No significant differences were observed between $\mathrm{NPK}_{75}$ and $\mathrm{NPK}_{100 \%}$ mineral fertilizers. When the soil salinity level increased to $8-12 \mathrm{dSm}^{-1}$, the wheat grain yield decreased. The grain yield was $1.991 \mathrm{t} / \mathrm{ha}$ in plants inoculated with AM+Biotol under $\mathrm{NPK}_{100 \%}$ for Sakha 93, while it was 1.710 t/ha for Gemmeza 9. Significant differences in the grain yield (t/ha) were found between the two wheat cultivars. Sakha 93 recorded highest value of grain yield, compared to Gemmeza 9 under high level of soil salinity.

\section{Grain protein}

Wheat plants Inoculated with G. intraradices alone or G. intraradices + Biotol resulted high values of protein content of wheat grains for both cultivars. Under normal salinity levels $\leq 4 \mathrm{dSm}^{-1}$, the highest grain protein content was obtained in case of plants inoculated with mycorrhizal fungus and Biotol (1.39\%) for Gemmeza variety at $\mathrm{NPK}_{75 \%}$. Under salinity level 8-12 $\mathrm{dSm}^{-1}$ the highest protein content was obtained from both cultivars in the presence of $\mathrm{NPK}_{100 \%}$ with percentage increases 36.31 and $43.96 \%$ more than un-inoculated plants, for Sakha 93 and Gemmeza 9, respectively. Significant differences in protein contents were found between the two cultivars, Gemmeza 9 recorded the highest value compared to Sakha 93 (Table 11).

\section{Proline content}

Significant differences in shoot proline contents among the two wheat cultivars were recorded by increasing soil salinity levels. Sakha 93 recorded higher values of proline than Gemmeza 9 (Table 12). Data clearly show positive effect of AM inoculation on proline content under the tested levels of soil salinity.

\section{Salicylic acid}

Dual inoculation with $\mathrm{G}$. intraradices and Biotol significantly increased the salicylic acid concentration at all the tested levels of soil salinity. The percentage increases, as compared to uninoculated control was reached 192.57 and 135.42 for Sakha 93 and Gemmeza 9, respectively, in the presence of $\mathrm{NPK}_{75 \%}$ and soil salinity 8-12 dSm${ }^{-1}$ (Table 13). 


\section{DISCUSSION}

Salinity represents one of the most important environmental stresses since it limits crop plant production which is contrary to the increased demand for food all over the world. Therefore, the studies of salinity tolerance in plants consider a special importance. From the above results we concluded that, wheat inoculated with AM fungus showed significant increases in the percentage of AMF colonization and growth yield parameters compared to un-inoculated plants under different levels of soil salinity. It was clear that, by increasing soil salinity, the percentage of AMF colonization and growth yield parameters significantly decreased. Aroca et al. (2013) found that, increasing soil salinity levels lowered the percentage of mycorrhizal root colonization in lettuce plants. Miransari et al. (2007) observed that, Zea mays plant inoculated with AM fungi (Glomus mosseae and Glomus etunicatum) 
Table (9). Effect of wheat inoculation with Glomus intraradices and Biotol on 1000 grains weight $(\mathrm{g})$ in the presence of four levels of soil salinity (averages of the two seasons 2012/2013 and 2013/2014)

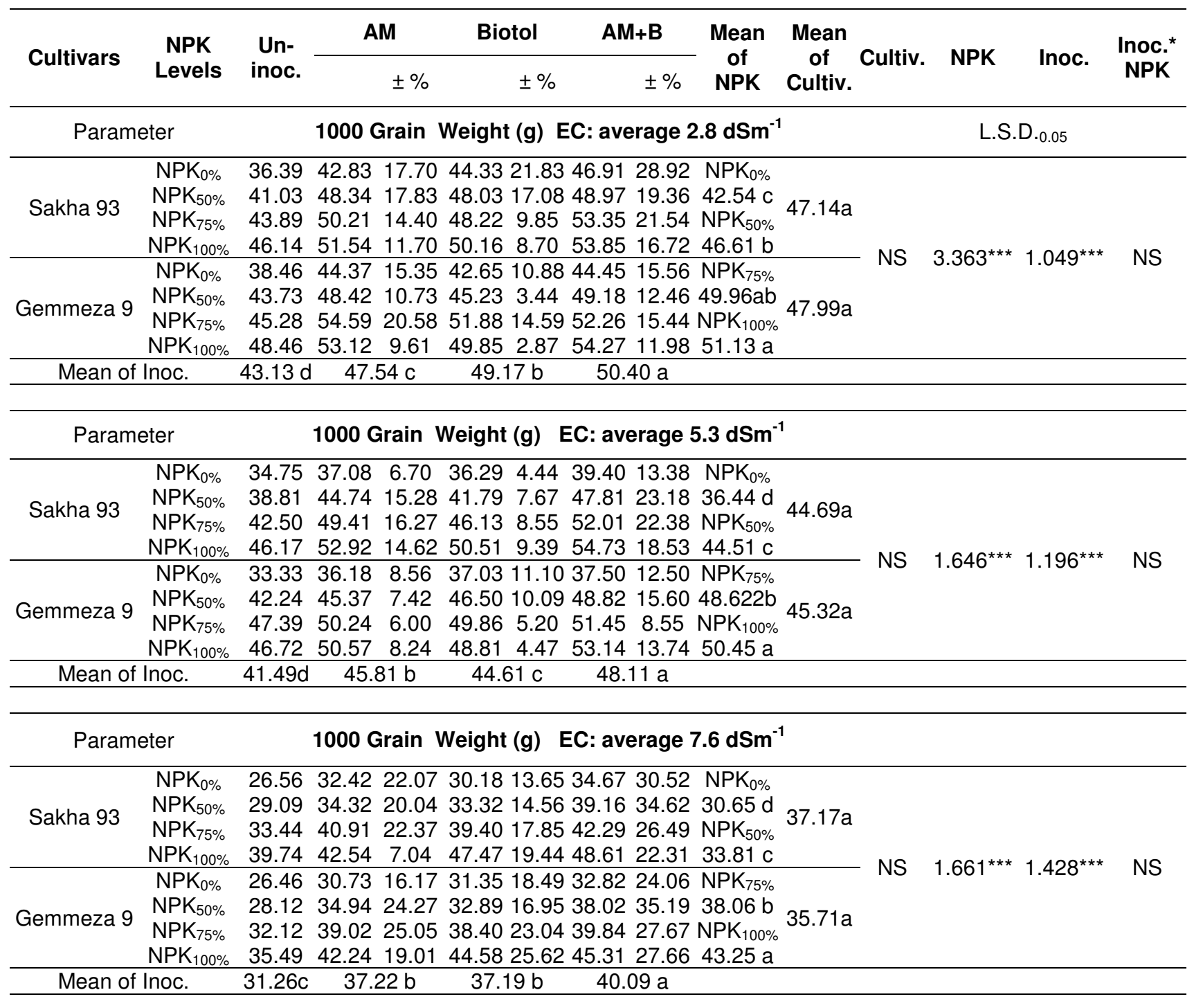

Parameter

1000 Grain Weight (g) EC: average $10.5 \mathrm{dSm}^{-1}$

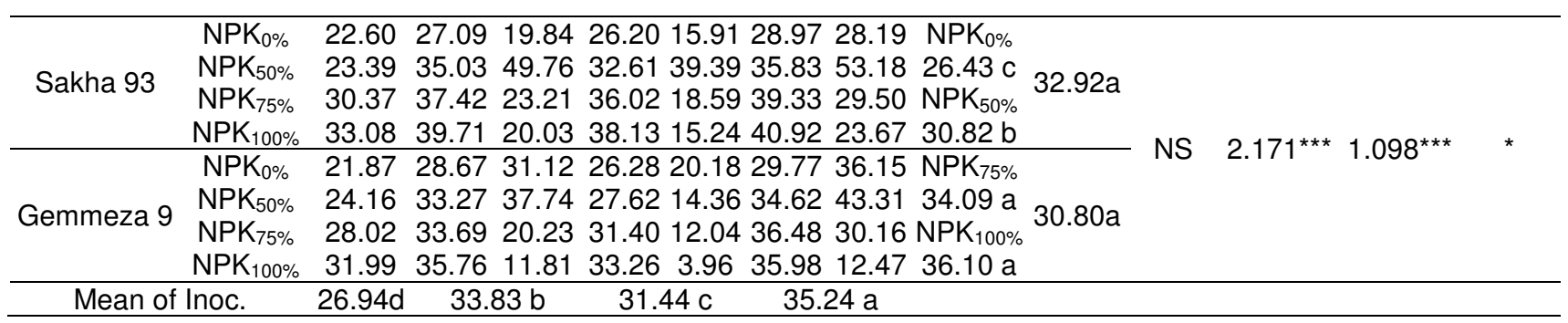

$\pm \%$ Increase or decrease to uninoculated (control) plants 
Table (10). Effect of wheat inoculation with Glomus intraradices and Biotol on grains yield $(\mathrm{t} / \mathrm{ha})$ in the presence of four levels of soil salinity (averages of the two seasons 2012/2013 and 2013/2014)

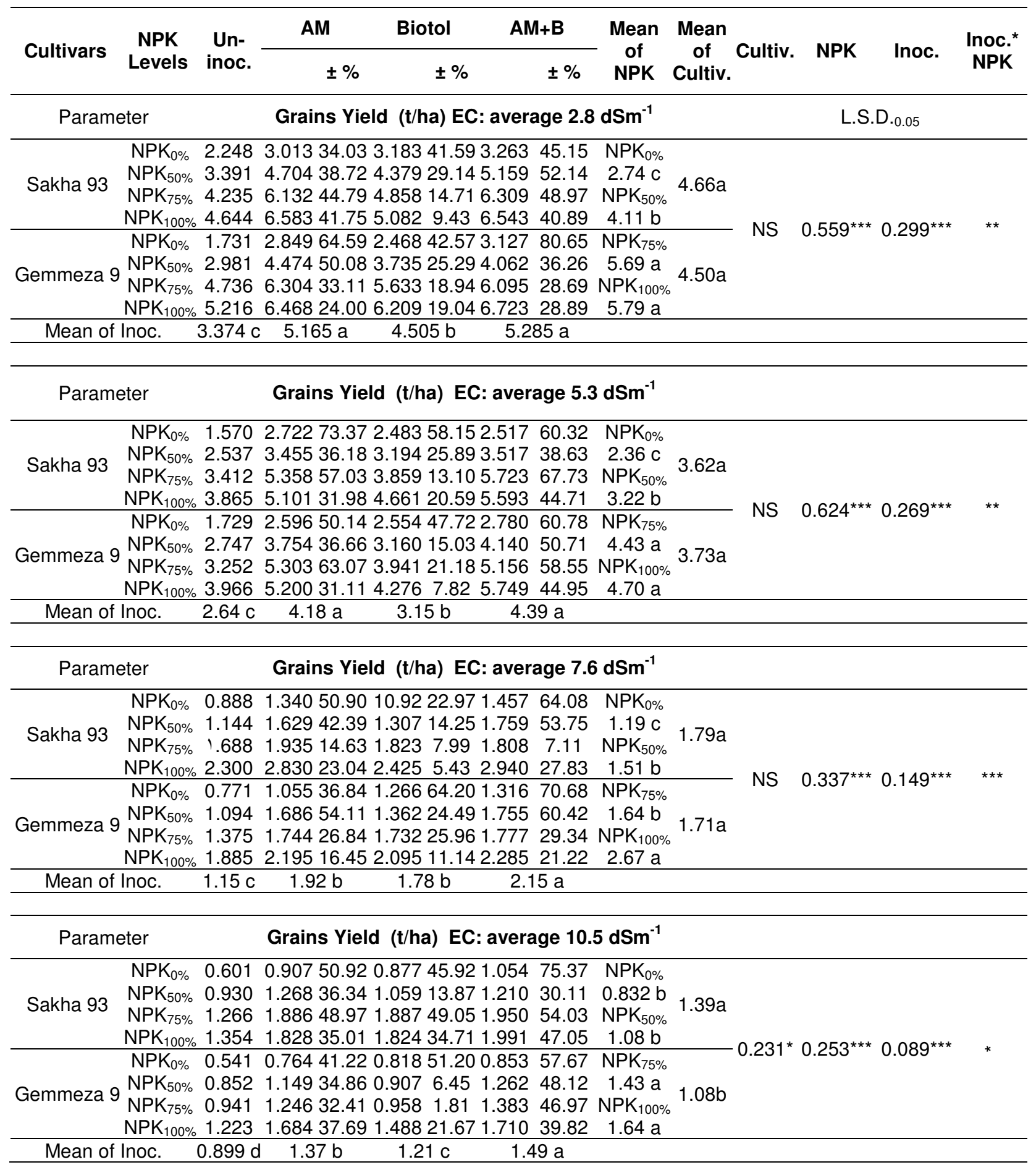

$\pm \%$ Increase or decrease to uninoculated (control) plants 
Table (11). Effect of wheat inoculation with Glomus intraradices and Biotol on Protein (\%) in the presence of different levels of soil salinity (averages of the two seasons 2012/2013 and 2013/2014)

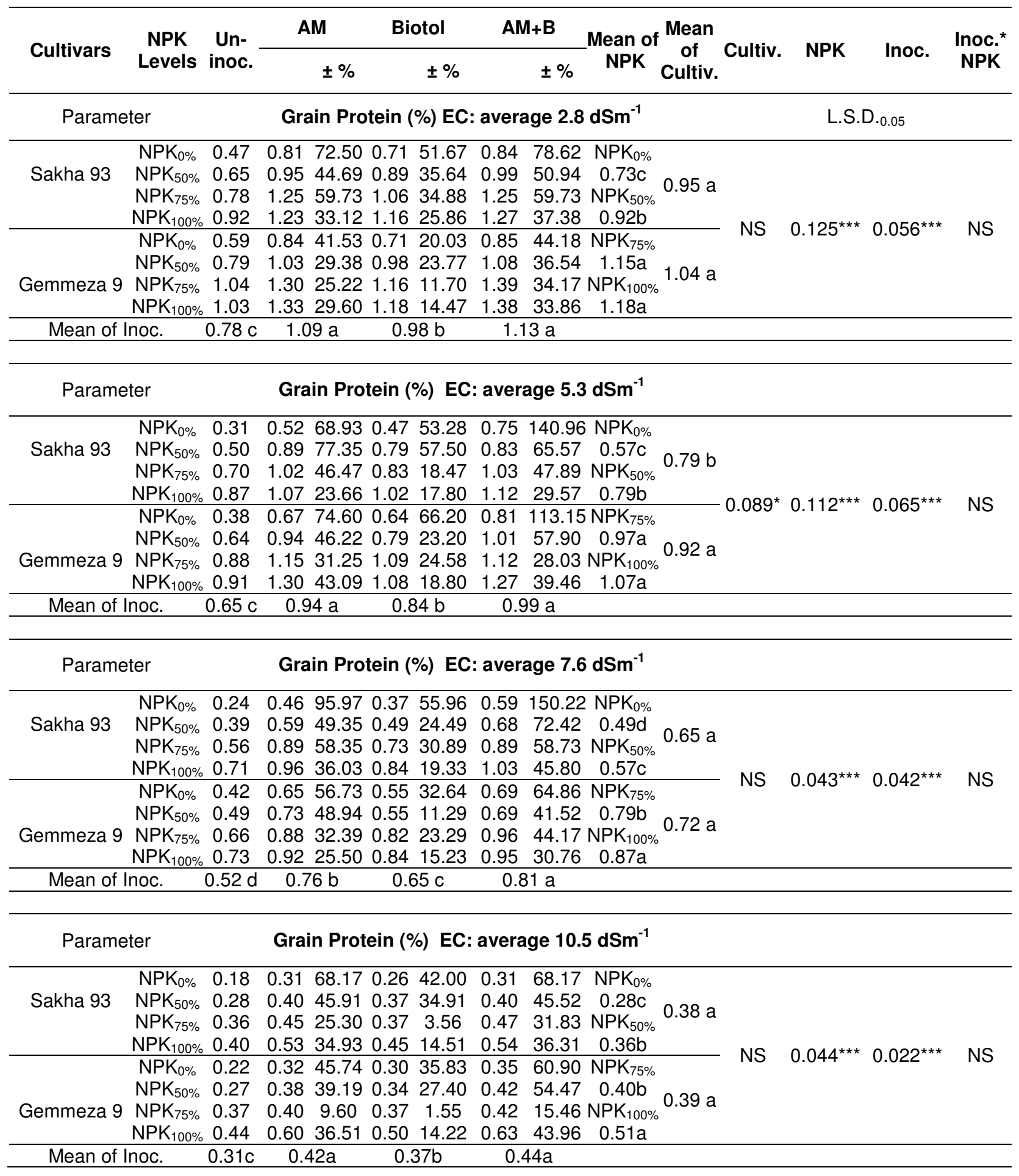

$\pm \%$ Increase or decrease to uninoculated (control) plants 
Table (12). Effect of wheat inoculation with Glomus intraradices and Biotol on proline ( $\mathrm{mg} / \mathbf{1 0 0} \mathrm{g}$ shoot dry wt.) in the presence of four levels of soil salinity (averages of the two seasons 2012/2013 and 2013/2014)

\begin{tabular}{|c|c|c|c|c|c|c|c|c|c|c|c|c|c|c|}
\hline \multirow{2}{*}{ Cultivars } & \multirow{2}{*}{$\begin{array}{c}\text { NPK } \\
\text { Levels }\end{array}$} & \multirow{2}{*}{$\begin{array}{l}\text { Un- } \\
\text { inoc. }\end{array}$} & \multicolumn{2}{|c|}{ AM } & \multicolumn{2}{|c|}{ Biotol } & \multicolumn{2}{|c|}{$A M+B$} & \multirow{2}{*}{$\begin{array}{c}\text { Mean } \\
\text { of } \\
\text { NPK }\end{array}$} & \multirow{2}{*}{$\begin{array}{l}\text { Mean } \\
\text { of } \\
\text { Cultiv. }\end{array}$} & \multirow{2}{*}{ Cultiv. } & \multirow{2}{*}{ NPK } & \multirow{2}{*}{ Inoc. } & \multirow{2}{*}{$\begin{array}{l}\text { Inoc. }{ }^{*} \\
\text { NPK }\end{array}$} \\
\hline & & & & $\pm \%$ & & $\pm \%$ & & $\pm \%$ & & & & & & \\
\hline \multicolumn{2}{|c|}{ Parameter } & \multicolumn{9}{|c|}{ Proline content (mg/100 g shoot dry wt.) EC: average $2.8 \mathrm{dSm}^{-1}$} & \multicolumn{4}{|c|}{ L.S.D.0.05 } \\
\hline Sakha 93 & $\begin{array}{l}\mathrm{NPK}_{0 \%} \\
\mathrm{NPK}_{50 \%} \\
\mathrm{NPK}_{75 \%} \\
\mathrm{NPK}_{100 \%}\end{array}$ & $\begin{array}{l}42.73 \\
63.68 \\
74.76 \\
86.17\end{array}$ & $\begin{array}{c}59.65 \\
83.15 \\
109.86 \\
123.43 \\
\end{array}$ & $\begin{array}{l}39.60 \\
30.58 \\
46.95 \\
43.23\end{array}$ & $\begin{array}{c}59.07 \\
73.31 \\
89.15 \\
108.70\end{array}$ & $\begin{array}{l}38.24 \\
15.13 \\
19.24 \\
26.14\end{array}$ & $\begin{array}{c}64.92 \\
89.04 \\
111.76 \\
129.39 \\
\end{array}$ & $\begin{array}{l}51.93 \\
39.82 \\
49.49 \\
50.15\end{array}$ & $\begin{array}{c}\mathrm{NPK}_{0 \%} \\
57.47 \mathrm{~d} \\
\mathrm{NPK}_{50 \%} \\
84.16 \mathrm{c}\end{array}$ & $85.54 a$ & \multirow[b]{2}{*}{ NS } & \multirow[b]{2}{*}{$9.167^{\star * *}$} & \multirow[b]{2}{*}{$4.981^{* * *}$} & \multirow[b]{2}{*}{ * } \\
\hline Gemmeza 9 & $\begin{array}{l}\mathrm{NPK}_{0 \%} \\
\mathrm{NPK}_{50 \%} \\
\mathrm{NPK}_{75 \%} \\
\mathrm{NPK}_{100 \%}\end{array}$ & $\begin{array}{l}47.98 \\
68.35 \\
77.11 \\
98.42 \\
\end{array}$ & $\begin{array}{c}60.37 \\
103.67 \\
117.44 \\
121.09 \\
\end{array}$ & $\begin{array}{l}25.84 \\
51.67 \\
52.29 \\
23.03 \\
\end{array}$ & $\begin{array}{c}62.24 \\
84.02 \\
107.48 \\
109.26 \\
\end{array}$ & $\begin{array}{l}29.74 \\
22.93 \\
39.37 \\
11.01 \\
\end{array}$ & $\begin{array}{c}62.75 \\
108.07 \\
126.63 \\
119.05 \\
\end{array}$ & $\begin{array}{l}30.79 \\
58.11 \\
64.21 \\
20.96 \\
\end{array}$ & $\begin{array}{l}\mathrm{NPK}_{75 \%} \\
101.77 \mathrm{~b} \\
\mathrm{NPK}_{100 \%} \\
111.94 \mathrm{a} \\
\end{array}$ & $92.12 \mathrm{a}$ & & & & \\
\hline Mean of & Inoc. & $69.90 \mathrm{c}$ & 97.3 & $33 \mathrm{a}$ & 86.6 & $5 \mathrm{~b}$ & 101 & $45 \mathrm{a}$ & & & & & & \\
\hline
\end{tabular}

Parameter

Proline content (mg/100 g shoot dry wt.) EC: average $5.3 \mathrm{dSm}-1$

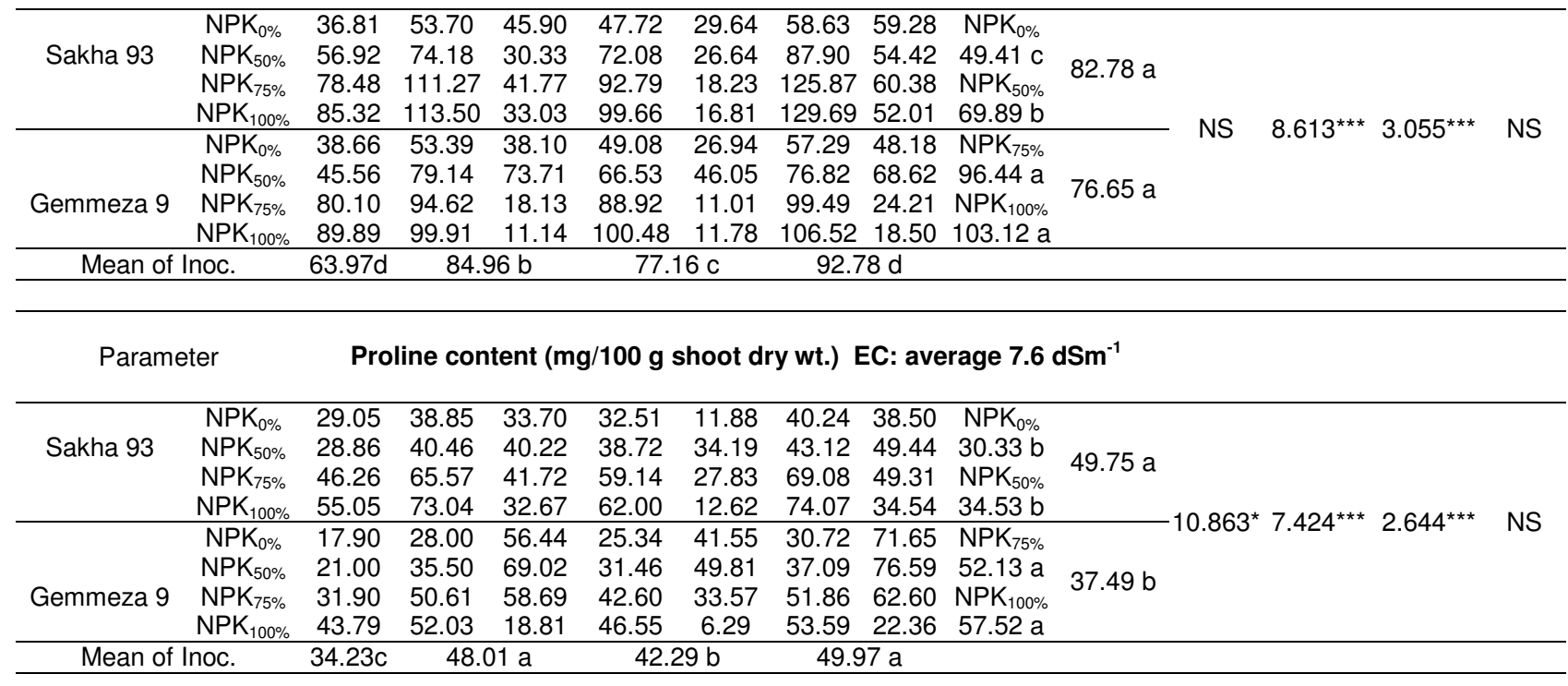

Parameter Proline content (mg/100 g shoot dry wt.) EC: average $10.5 \mathrm{dSm}^{-1}$

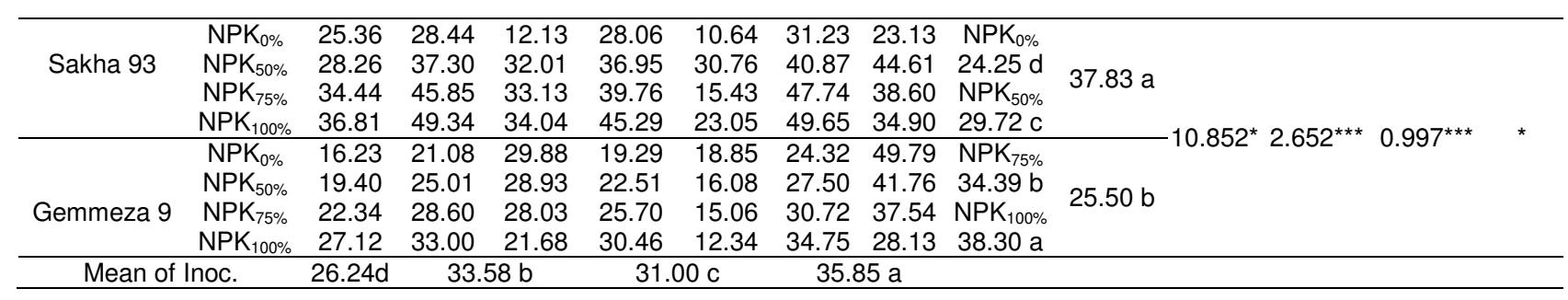

$\pm \%$ Increase or decrease to uninoculated (control) plants 
Table (13). Effect of wheat inoculation with Glomus intraradices and Biotol on salicylic acid $(\mathrm{mg} / 100 \mathrm{~g}$ root fresh wt.) in the presence of four levels of soil salinity (averages of the two seasons 2012/2013 and 2013/2014)

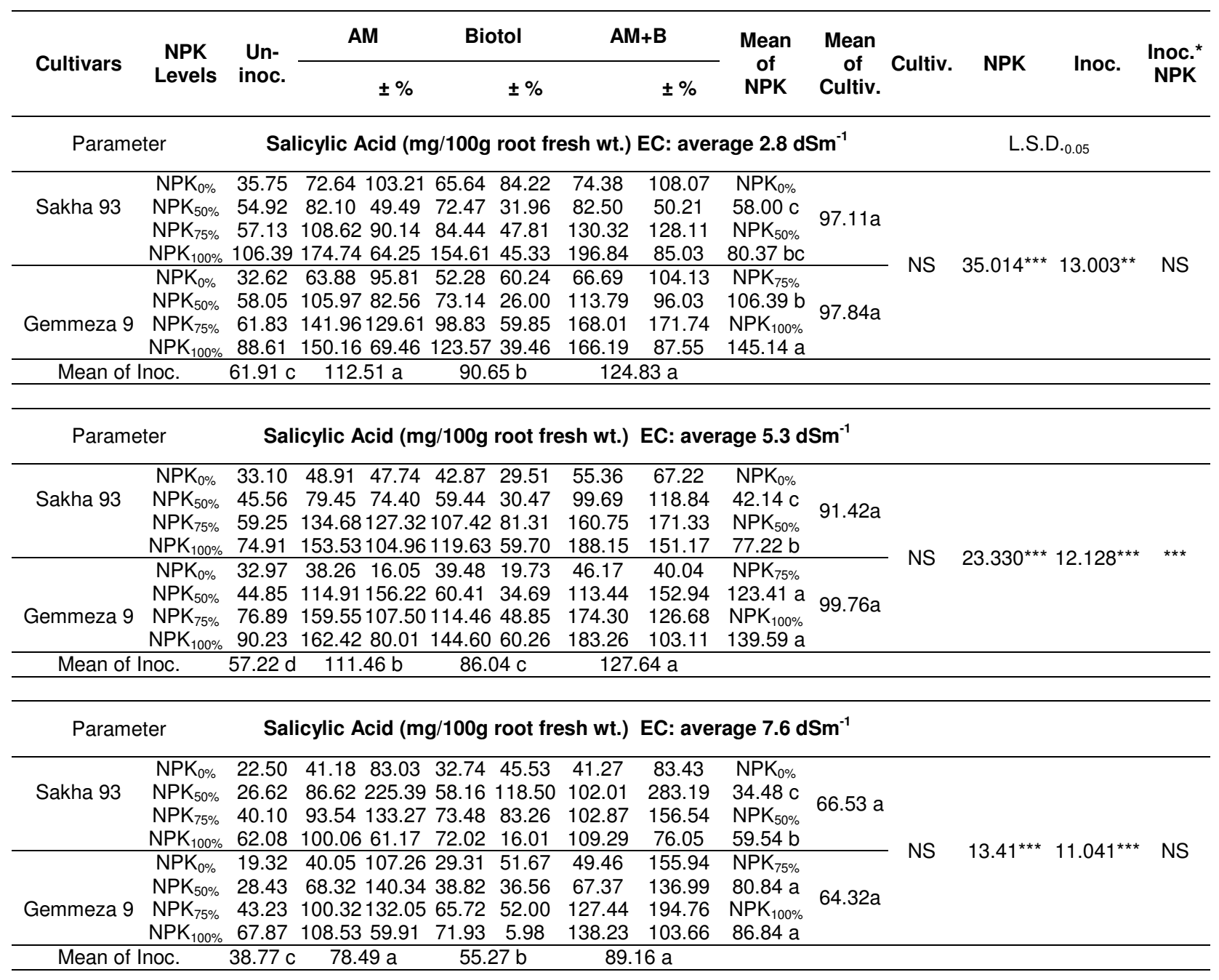

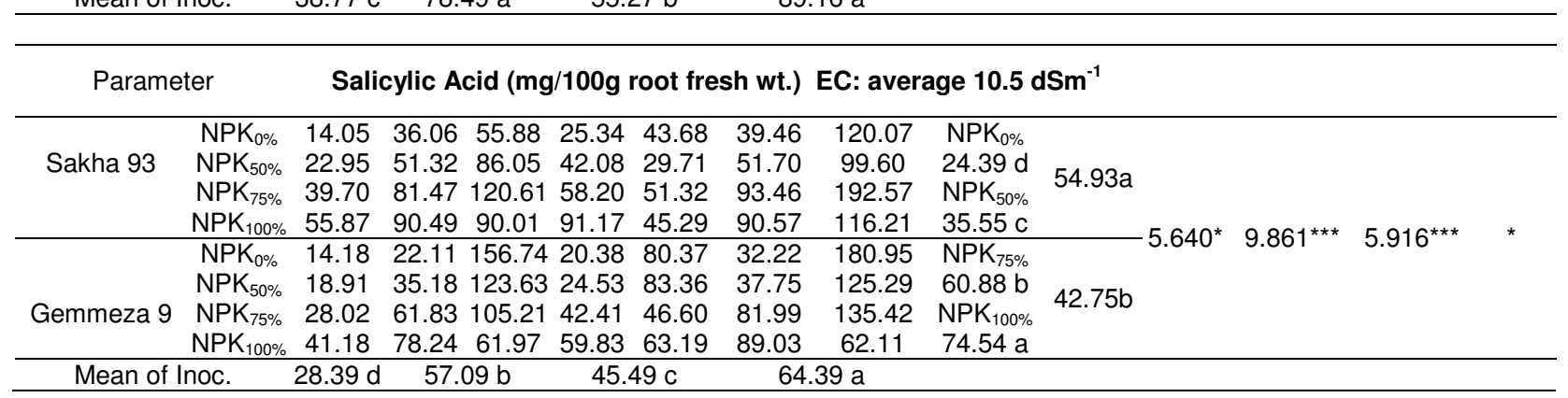

$\pm \%$ Increase or decrease to uninoculated (control) plants 
Showed significant increases in shoot and root dry weights and root length compared to uninoculated plants under field conditions. The results also show that, the lowest values of $\mathrm{Na}$ contents $(\mathrm{mg} / \mathrm{kg})$ were observed under $\mathrm{EC} \leq 4 \mathrm{dSm}-1$ for plants inoculated with G. intraradices and Biotol under NPK100\% for Sakha 93 and Gemmeza 9. The increased photosynthetic pigments by mycorrhizal colonization in plants is due to the inhibition of $\mathrm{Na}+$ transport, which leads to better functioning of photosynthetic machinery (Borde et al. 2010; García-Garrido and Ocampo, 2002). Ragab et al. (2008) reported that, when irrigation wheat plants with different levels of salinity led to an increase in the concentration of the sodium component of wheat plants, and decrease NPK uptake, 1000 grain wt. and grain yield compared to wheat plants growing in low salinity. Daughtry et al. (2000) and Bojović and Markovic (2009), indicated that, inoculated wheat plant Triticum aestivum with AM fungi significantly increased chlorophyll content compared to uninoculated plants. Since mycorrhization increases the absorption of $\mathrm{Mg}++$ in plants, the synthesis of chlorophyll increases in mycorrhizal plants. Increasing chlorophyll activity in AM-inoculated plants decreases $\mathrm{Na}+$ level under salt stress. The results also show that, inoculation with the AM fungus and Biotol, significantly increased proline and salicylic acid content when compared to uninoculated ones under different levels of soil salinity. Proline accumulation is one of the natural means to adapt to environmental stress conditions. Proline is a non-toxic and good osmolyte and maintains the osmoregulation under salt stress (Rasool et al. 2013a, b). Kumar et al. (2011) reported that, wheat plant inoculated with Glomus mosseae contained increased proline levels compared to non inoculated plants. Salicylic acid (SA), a plant phenolic, is considered as a hormone like endogenous regulator, and its role in the defence mechanisms against biotic and abiotic stresses has been well characterized, (Szalai et al. 2009). It also plays an important role in plant growth and plant defense responses to pathogen attack local (hypersensitive response) and systemic acquired resistance, (Durner and Klessig 1996). Zhang et al. (2013) reported that, inoculated wheat plants with AM fungi significantly increased salicylic acid contents compared to non AM-inoculated plants. Wheat plants Inoculated with $G$. intraradices alone or $G$. intraradices + Biotol resulted high values of NPK uptake, grain yield and protein contents of wheat grains for both cultivars. Zhu et al. (2010) and Mardukhi et al. (2011) reported that, wheat plant inoculated with AM fungi significantly increased NPK uptake compared to non AM-inoculated wheat plants. Sari, et al. (2002) reported similar results in garlic plants. Douds et al. (2005) and Ortas et al. (2001) confirmed that the AM hyphae increase the total absorption surface in infected plants which improve its access of immobile elements such as P, Cu, Zn. Kumar et al. (2011) and Bojović and Marković (2009) showed that, inoculated wheat plant with AM fungi showed significant increase in 1000 grain weight and grain yield compared to uninoculated plants. Mycorrhizal colonization can enhance $\mathrm{K}+$ absorption under saline conditions (Sharifi et al. 2007; Zuccarini and Okurowska, 2008). Nia et al. (2012) reported that, wheat plants inoculated with two Azospirillum isolates increased salinity tolerance, the saline-adapted isolate significantly increased grain yield. Afzal and Bano (2008), indicated that, wheat plant Triticum aestivum inoculated with Rhizobium strains significantly increased in grain yield, P content and protein content compared to uninoculated plants. Richardson et al. (2009), 
showed that, plants inoculated of with Bacillus and Paenibacillus increased plant growth parameters compared to un-inoculated plants.

\section{REFERENCES}

Aboul-Nasr, A. (1993). Identification of VA- mycorrhizal fungi in soil of Alexandria Governorate. Alex. J. Agri. Res., 38 (2): 371-376.

Aboul-Nasr, A. (2004). Method of producing an inoculum of endomycorrhizal fungi.; Academy Sci. Res. and Tech. Egypt. Patent No. 23234.

Afzal, A. and A. Bano (2008). Rhizobium and phosphate solubilizing bacteria improve the yield and phosphorus uptake in wheat (Triticum aestivum). Int. J. Agric. Biol., 10:85-88.

Aroca, R., J.M. Ruiz-Lozanoa and A.M. Zamarreno (2013). Arbuscular mycorrhizal symbiosis influences strigolactone production under salinity and alleviates salt stress in lettuce plants. J. Plant Physiol., 170: 47- 55.

Artursson, V., R.D. Finlay and J. Jansson (2006). Interactions between arbuscular mycorrhizal fungi and bacteria and their potential for stimulating plant growth. Environ. Microbiol., 8:1-10.

Awad, A.M., H.M. Ramadan and M.E. El-Fayoumy (1996). Effect of sulfur, phosphorus and nitrogen fertilizer on micronutrients availability, uptake and wheat production on calcareous soils. Alex. J. Agri. Res., 41(4): 311-327.

Azcon, R. and F. El-Atrash (1997). Influence of arbuscular mycorrhizae and phosphorus fertilization on growth, nodulation and $\mathrm{N}_{2}$ fixation $(15 \mathrm{~N})$ in Medicago sativa at four salinity levels. Biol. Fertil. Soils, 24: 81-86.

Bojović, B. and A. Marković (2009). Correlation between nitrogen and chlorophyll content in wheat (Triticum aestivum L.). Kragujevac J. Sci., 31: 69-74.

Bordes, A., N. Usunier, R. Collobert, and J. Weston (2010). Towards understanding situated natural language. In Proc. of the 13th Intern. Conf. on Artif. Intel. and Stat., 9: 65-72.

Chapman, H.D. and P.F. Pratt (1978). Methods of Analysis for soil, plant and waters. Univ. of California. Div. Agri. Sci., Priced publication 4043.

Cho, K., H. Toler, J. Lee, B. Owenley, J.C. Stutz, J.L. Moore and R.M. Auge (2006). Mycorrhizal symbiosis and response of sorghum plants to combined drought and salinity stresses. J. Plant Physiol., 163, 517-528.

Dai, A., T. Qian, K.E. Trenberth and J.D. Milliman (2009). Changes in continental freshwater discharge from 1948-2004. J. Climate, 22: 27732791

Daughtry, C.S.T., C.I. Walthall, M.S. Kim, B.D.E. Colstoun, and J. E. Mcmurtrey (2000). Estimating corn leaf chlorophyll concentracion from leaf and canopy reflectance. Rem. Sens. Environ., 74: 229-239.

Dimkpa, C., Weinand T. and F. Ash (2009). Plant-rhizobacteria interactions alleviate abiotic stress conditions. Plant Cell Environ., 32: 1682-1694.

Douds, D.D., G. Nagahasha, P.E. Pfeffer, W.M. Kayser and C. Reider (2005). On farm production and utilization of arbuscular mycorrhizal fungus inoculum. Can. J. Plant Sci., 85: 15-21. 
Durner, J. and D.F. Klessig (1996). Salicylic acid is a modulator of tobacco and mammalian catalases, Plant Mol. Biol., 28: 28492-28501.

Evelin, H.; R. Kapoor and B. Giri (2009). Arbuscular mycorrhizal fungi in alleviation of salt stress: a review. Annals of Botany;104:1263-1280.

Figueiredo, L., C. Janzen and G. Cross (2008). A histone methyltransferase modulates antigenic variation in African trypanosomes. PLoS Biol., 6, e161.

Ganji Arjenaki, F., R. Jabbaril and A. Morshedi (2012). Evaluation of drought stress on relative water content, chlorophyll content and mineral elements of wheat (Triticum aestivum I.) cultivars. Int. J. Agric Crop Sci., 4 (11), 726729.

García-Garrido, J.M. and J.A. Ocampo (2002). Regulation of the plant defence response in arbuscular mycorrhizal symbiosis. J. Exp. Bot., 53:1377-1386.

Giovannetti, M. and B. Mosse (1980). An evaluation of methods for measuring vesicular arbuscular mycorrhizal infection in roots. New Phytol., 84: 489500.

Giri, B. and K.G. Mukerji (2004). Mycorrhizal inoculant alleviates salt stress in Sesbania aegyptiaca and Sesbania grandiflora under field conditions: evidence for reduced sodium and improved magnesium uptake. Mycorrhiza, 14: 307-312.

Hilal, M.H., H. El-Lakkany and H. El-Shemey (1990). Effect of sulfur and long term fertilizer application program on rhizosphere activity and yield pf peanuts in a sandy soil. Middle East Sulfur Symp., Cairo, 12-16 Feb., pp. 217-227.

Hurkman, W.J., C.S. Fornari and C.K. Tanaka (1989). A comparison of the effect of salt on polypeptides and translatable mRNA:j in roots of a salt-tolerant and a salt-sensitive cultivar of barley. Plant Physiol., 90: 1444-1456.

Iqbal, A. and F. Vaid (2009). Determination of benzoic acid and salicylic acid in commercial benzoic and salicylic acid ointments by spectrophotometer method. Pak. J. Pharm. Sci. 22: 18-22.

Jackson, M. L. (1973). Soil Chemical Analysis Prentice Hall of India Pvt. Ltd. New Delhi.

Juniper, S. and L.K. Abbott (1993). Vesicular-arbuscular mycorrhizas and soil salinity. Mycorrhiza, 4: 45-57.

Klute, A. (1986). Methods of Soil Analysis Part 1,2 $2^{\text {nd }}$ ed., Agron. Monor. G.ASA and SSSA, Madison, W.I.

Kohler, J., F. Caravaca, L. Carrasco and A. Roldan (2006). Contribution of Pseudomonas mendocina and Glomus intraradices to aggregates stabilization and promotion of biological properties in rhizosphere soil of lettuce plants under field conditions. Soil Use Manage., 22, 298-304.

Kohler, J., J.A. Hernandez, F. Caravaca and A. Roldan (2009). Induction of antioxidant enzymes is involved in the greater effectiveness of a PGPR versus $A M$ fungi with respect to increasing the tolerance of lettuce to severe salt stress. Environ. Exp. Bot., 65: 245-252.

Koske, A.E. and J.N. Gemma (1989). A modified procedure for staining roots to detect VA mycorrhizas. Mycol. Res., 92 (4): 486-488.

Kumar, A., K.D. Sharma and R. Gera (2011). Arbuscular mycorrhizae (Glomus mosseae) symbiosis for increasing the yield and quality of wheat (Triticum aestivum). Indian j. Agric. Sci., 81 (5): 478-80. 
Lowther, G.R. (1980). Use of a single H2SO4 - H2O2 digest for the analysis of Pinus radiate needles. Commun. Soil Sci. Plant Anal., 11: 175-188.

Malamy, J., J. Hennig and D.F. Klessing (1992). Temperature dependent induction of salicylic acid and its conjugates during the resistance response to tobacco mosaic virus infection, plant cell, 4: 359-366.

Manske, G.G.B., J.I. Ortiz-Monasterio, M.V. Ginkel, R.M. Gonzalez, S. Rajaram, E. Molina and P.L.G. Vlek (2000). Traits associated with improved $P$ uptake efficiency in CIMMYT'S semi dwarf spring bread wheat grown on an acid Andisol in Mexico. Plant Soil, 221: 189-204.

Mardukhi, B., F. Rejali, G. Daei, M. R. Ardakani, M. J. Malakouti and M. Miransari (2011). Arbuscular mycorrhizas enhance nutrient uptake in different wheat genotypes at high salinity levels under field and greenhouse conditions. C. R. Biologies, 334: 564-571.

Miransari, M., H.A. Bahrami, F. Rejali, M.J. Malakouti and H. Torabi (2007). Using arbuscular mycorrhiza to reduce the stressful effects of soil compaction on corn (Zea mays L.) growth. Soil Bio. and Biochem., 39: 2014-2026.

Munns, R., S. Husain, Rivelli, R.A. James, A.G. Condon, M.P. Lindsay, E.S. Lagudah; D.P. Schachtman and R.A. Hare (2002). Avenues for increasing salt tolerance of crops, and the role of physiologically based selection traits. Plant Soil 247 (1), 93-105.

Nia, H. Somayeh, M. J. Zarea, F. Rejali and A. Varma (2012). Yield and yield components of wheat as affected by salinity and inoculation with Azospirillum strains from saline or non-saline soil. J. Saudi Soc. Agric. Sci., 11, 113-121.

Ortas, i., Z. kaya, I. Cakmak, W.j. Horst, M.K. Schenk, A. Burkert, N. Claassen, H. Flessa, W.B. Frommer, H. Glodbach, H.W. Olfs, and V. Romheld (2001). Influence of arbuscular mycorrhizae inoculation on growth of maize and green pepper plants in phosphorus and zinc-deficient soil. Plant Nutrition, Col. Hannover, Germany, pp. 632-633.

Page, A.L., R.H. Miller and D.R. Keeny (1982). Methods of Soil Analysis .Amer. Soc. Agric. Inc. Madison.

Pérez-Alfocea, F., A. Albacete, M.E. Ghanem and I.C. Dodd (2010). Hormonal regulation of source-sink relations to maintain crop productivity under salinity: A case study of root-to-shoot signalling in tomato. Funct. Plant Biol., 37, 592-603.

Ragab, A.A.M., F.A. Hellal and M. Abd El-Hady (2008). Water salinity impacts on some soil properties and nutrients uptake by wheat Plants in sandy and calcareous soil. Australian J. Basic and Appl. Sci., 2(2): 225-233.

Rasool, S., A. Ahmad, T.O. Siddiqi and P. Ahmad (2013a). Changes in growth, lipid peroxidation and some key antioxidant enzymes in chickpea genotypes under salt stress. Acta Physiol. Plant., 35(4):1039-1050.

Rasool, S., A. Hameed, M.M. Azooz, T.O. Siddiqi and P. Ahmad (2013b). Salt stress: causes, types and responses of plants. In: Ahmad P, Azooz MM, Prasad MNV (ed) Ecophysiology and Responses of Plants under Salt Stress, Springer New York, pp. 1-24. 
Richardson, A.E., J.M. Barea, A.M. McNeill and C. Prigent-Combaret (2009). Acquisition of phosphorus and nitrogen in the rhizosphere and plant growth promotion by microorganisms. Plant Soil, 321:305-339.

Ruiz-Lozano, J.M. and R. Azcon (2000). Symbiotic efficiency and infectivity of an autochthonous arbuscular mycorrhizal Glomus sp. from saline soils and Glomus deserticola under salinity. Mycorrhiza, 10: 137-143.

Sakhabutdinova, A.R., D.R.Fatkhutdinova, M.V. Bezrukova and F.M. Shakirova (2003). Salicylic acid prevents the damaging action of stress factors on wheat plants. Bulg J. Plant Physiol. 314-319.

Sari, N., B. Ortas and H. Yetisir (2002). Effect of mycorrhizae inoculation on plant growth, yield, and phosphorus uptake in garlic under field conditions. Communic. Soil Sci. and Plant Anal. 33 (13 and 14): 2189 - 2201.

Sharifi, M., M. Ghorbanli and H. Ebrahimzadeh (2007). Improved growth of salinity stressed soybean after inoculation with pre-treated mycorrhizal fungi. J. Plant Physiol. 164: 1144-1151.

Sheng, X.R., T. Posenau, J.J. Gumulak-Smith, E. Matunis, Van M. Doren and M. Wawersik (2009). Jak-STAT regulation of male germline stem cell establishment during Drosophila embryogenesis. Dev. Biol., 334(2): 335-344.

Shrivastava, P. and R. Kumar (2015). Soil salinity: A serious environmental issue and plant growth promoting bacteria as one of the tools for its alleviation. Saudi J. of Biological Sci., 22: 123-131.

Snedecor, G.W. and W.G. Cochran (1982). Statistical methods. The lowa State Univ. Press. $7^{\text {th }}$ Ed.. $2^{\text {nd }}$ Printing. $p 507$.

Szalai, G., T. Kellos, G. Galiba and G. Kocsy (2009). Glutathione as an antioxidant and regulatory molecule in plants under abiotic stress conditions. J. Plant Growth Regul., 28: 66-80.

Tank, N. and M. Saraf (2010). Salinity-resistant plant growth promoting rhizobacteria ameliorates sodium chloride stress on tomato plants. J. Plant Interact. 5: 51-58.

Tawfik, K.P., Bahr A. Amany, and A.K.M. Salem (2006). Response of Kaller grass (Leptochloafuscal L.) to biofertilizer inoculation under different levels of sea water irrigation. J. Appl. Sci. Res., 2(12): 1023-1211.

Umbreit, W.W., R.H. Burris and J.F. Stauffer (1972). Manometric and biochemical techniques. Burgess Publishing Company.

Wu, M.N., W.J. Joiner, T. Dean, Z. Yue, C.J. Smith, D. Chen; T. Hoshi, A. Sehgal, and K. Koh (2010). Sleepless, a Ly-6/neurotoxin family member, regulates the levels, localization and activity of Shaker. Nat. Neurosci., 13(1): 69--75.

Zhang, R.Q., H.H. Zhub, H.Q. Zhaoc and Q. Yao (2013). Arbuscular mycorrhizal fungal inoculation increases phenolic synthesis in clover roots via hydrogen peroxide, salicylic acid and nitric oxide signaling pathways. J. Plant Physiol., 170: 74- 79.

Zhu, B., C. Chen, E.F. Loftus, C. Lin, Q. He and C. Chen (2010). Individual differences in false memory from mis information: Personality characteristics and their interactions with cognitive abilities. Personality and Individual Differences, 48: 889-894. 
Zuccarini, P. and P. Okurowska (2008). Effects of mycorrhizal colonization and fertilization on growth and photosynthesis of sweet basil under salt stress. J. Plant Nutrition, 31: 497-513.

$$
\text { الملخص العربي }
$$

\section{امكانية استخدام فطر Glomus intraradices وعزلات مختلفة من البكتيريا المنشطة للجذور النباتية (Biotol) لتحسين محصول وجودة القمح النامي في الحقل تحت مستويات مختلفة من ملوحة التربة الجيرية}

\section{أمال أبوالنصر ' ؛ محمد عصمت الفيومي' ؛ ماجدة ابوالمجدَّو أحمد الهباب'} ا ـ قسم النبات الزراعي، الميكروبيولوجيا الزراعية ، كلية الزراعة سابا باثـا ، جامعة الإسكندرية. r. معهد الأراضي والمياه والبيئة ، مركز البحوث الزراعية ، محطة بحوث النوبارية. r. قسم الاراضي والكيمياء الزراعية ، تغذية النبات وخصوبة الأراضي ، كلية الزراعة سابا باشا ، جامعة الإسكندرية.

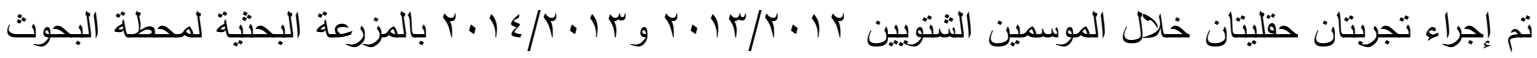
الزراعية بالنوبارية (الأراضي الجيرية). بهدف دراسة تأثثر التلقيح بفطر الميكوريزا الداخلية وبكتريا الجذور المحفزة لنمو

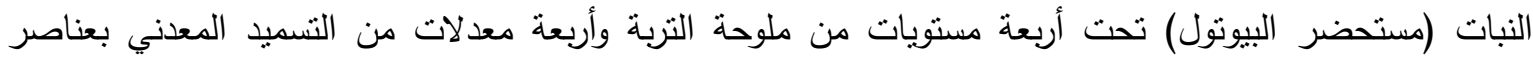
النيتروجين والفوسفور والبوتاسيوم علي النمو ، الصفات المحصولية ، المحتوي الكيميائي لصنفين من القمح (سخا به وجميزة 9) تحت ظروف التربة الجيرية. اشارت النتائج الي ان ثلقيح نباتات القمح بفطر الميكوريزا ومستحضر البيوتول معا ادي الي تقليل تركيز عنصر الصوديوم في النباتات لارجة معنوية وزيادة امتصاص عناصر النيتروجين والفوسفور والبوتاسيوم وايضا محتوي النباتات من البرولين ، حمض السليسليك ، الكلوروفيل ومحتوي الحبوب من البروتين تحت المستويات المختلفة من ملوحة التربة بالمقارنة بالنباتات غير الملقحة. تحت مستوي ملوحة التربة العادي ل4 dSm)

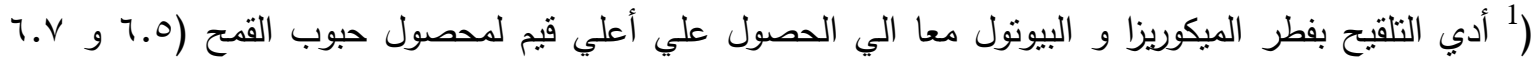
طن/هكتار) للأصناف سخا بو وجميزة 9 علي التوالي عند مستوي تسميد معدني NPK 100\% الموصي به في منطقة النوبارية بزيادة قدرها اء و qج \% عن النباتات غير الملقحة. أظهرت النتائج ايضا عدم وجود اختلافات معنوية بين النباتات الملقحة بالميكوريزا والبكتيريا المنشطة لنمو النبات عند مستوي تسميد معدني vo أو . . (\% من المعدلات

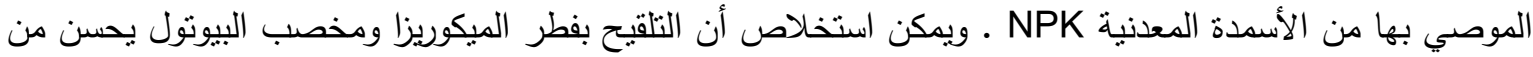
النمو وانتاجية نباتات القمح تحت نأنثير الإجهاد الملحي. 
